\title{
Spatial and Temporal Physiognomies of Whitefly and Tomato Yellow Leaf Curl Virus Epidemics in Southwestern Florida Tomato Fields
}

\author{
Daniel J. Anco, ${ }^{1}$ Lisa Rouse, ${ }^{2}$ Leon Lucas, ${ }^{3}$ Felicia Parks, ${ }^{3}$ H. Charles Mellinger, ${ }^{3}$ Scott Adkins, ${ }^{4}$ Chandrasekar S. Kousik, ${ }^{5}$ \\ Pamela D. Roberts, ${ }^{6}$ Philip A. Stansly, ${ }^{6}$ Miae Ha, ${ }^{4}$ and William W. Turechek ${ }^{4} \dagger$ \\ ${ }^{1}$ Clemson University, Edisto Research and Education Center, Blackville, SC, 29817 \\ 2 Washington State Department of Agriculture, Plant Protection Division, Anacortes, WA 98221 \\ ${ }^{3}$ Glades Crop Care, Inc., Jupiter, FL 33458 \\ ${ }^{4}$ United States Department of Agriculture-Agricultural Research Service (USDA-ARS), U.S. Horticultural Research Laboratory, Fort Pierce, \\ FL 34945 \\ ${ }^{5}$ USDA-ARS, U.S. Vegetable Laboratory, Charleston, SC 29414 \\ ${ }^{6}$ Southwest Florida Research and Education Center, University of Florida, Immokalee, FL \\ Accepted for publication 26 September 2019.
}

\begin{abstract}
Epidemics of tomato yellow leaf curl virus (TYLCV; species Tomato yellow leaf curl begomovirus) have been problematic to tomato production in the southeastern United States since the first detection of the virus in Florida in the late 1990s. Current strategies for management focus on farm-centric tactics that have had limited success for controlling either TYLCV or its whitefly vector. Areawide pest management (AWPM)-loosely defined as a coordinated effort to implement management strategies on a regional scale — may be a viable management alternative. A prerequisite for development of an AWPM program is an understanding of the spatial and temporal dynamics of the target pathogen and pest populations. The objective of this study was to characterize populations of whitefly and TYLCV in commercial tomato production fields in southwestern Florida and utilize this information to develop predictors of whitefly density and TYLCV disease incidence as a function of environmental and geographical factors. Scouting reports were submitted by cooperating growers located across approximately 20,000 acres in southwestern Florida from 2006 to 2012. Daily weather data were obtained from several local weather stations. Moran's I was used to assess spatial relationships and polynomial distributed lag regression was used

proportionally with mean whitefly density as the season progressed. Nearest-neighbor analyses showed a strong linear relationship between the logarithms of whitefly densities in neighboring fields. A similar relationship was found with TYLCV incidences. Correlograms based on Moran's $I$ showed that these relationships extended beyond neighboring fields and out to approximately $2.5 \mathrm{~km}$ for TYLCV and up to $5 \mathrm{~km}$ for whitefly, and that values of $I$ were generally higher during the latter half of the production season for TYLCV. Weather was better at predicting whitefly density than at predicting TYLCV incidence. Whitefly density was best predicted by the number of days with an average temperature between 16 and $24^{\circ} \mathrm{C}$ (T16to24), relative humidity (RH) over the previous 31 days, and vapor pressure deficit over the last 8 days. TYLCV incidence was best predicted by T16to24, RH, and maximum wind speed over the previous 31 days. Results of this study helped to identify the extent to which populations of whitefly and TYLCV exist over the agricultural landscape of southwestern Florida, and the environmental conditions that favor epidemic growth. This information was used to propose an approach to AWPM for timing control measures for managing TYLCV epidemics.
\end{abstract} to determine the relationship between weather variables, whitefly, and TYLCV. Analyses showed that the incidence of TYLCV increased
Keywords: ecology and epidemiology, virology
Florida is one of the leading states in the production of freshmarket tomato, the cornerstone of the state's winter vegetable industry. The mean annual production in dollars of Florida's fresh market tomato between the years 2001 and 2017 was a little over $\$ 488$ million, representing $40 \%$ of the total value of Florida's vegetable production (USDA-NASS 2012, 2018). There are many obstacles that threaten tomato production in Florida and the southeastern United States but, over the past 20 years, whitefly and

†Corresponding author: W. W. Turechek; william.turechek@ars.usda.gov

Funding: Financial support was provided, in part, by the USDA Cooperative Research and Extension Services Specialty Crop Research Initiative (SCRI) grant 2008-51180-19597 and USDA National Institute of Food and Agriculture SCRI grant 2018-51181-28420.

*The $\boldsymbol{e}$-Xtra logo stands for "electronic extra" and indicates that two supplementary figures and two supplementary tables are published online.

The author(s) declare no conflict of interest.

This article is in the public domain and not copyrightable. It may be freely reprinted with customary crediting of the source. The American Phytopathological Society, 2020. whitefly-transmitted viruses have consistently ranked near the top of the list.

Tomato yellow leaf curl virus (TYLCV; species Tomato yellow leaf curl begomovirus; genus Begomovirus; family Geminiviridae) is a whitefly-transmitted virus that is of great concern in Florida (Picó et al. 1996; Smith et al. 2019). TYLCV was first detected in southern Florida in 1997 (Polston et al. 1999) and shortly thereafter in northern Florida and southern Georgia in 1998 (Momol et al. 1999). The virus has subsequently been reported elsewhere in the Southeast, including Mississippi, South Carolina, and Alabama (Akad et al. 2007; Ingram and Henn 2001; Ling et al. 2006). TYLCV is resident year-round in tomato in southern Florida and becomes an issue in northern Florida and southern Georgia in late summer and early fall as the growing season progresses and production moves northward (Riley and Srinivasan 2019; Smith et al. 2019). The virus has appeared to varying degrees every year in Florida subsequent to its introduction, resulting in millions of dollars of lost production. TYLCV is transmitted by the silverleaf whitefly, Bemisia tabaci (Gennadius) Middle East-Asia Minor 1 (MEAM1) species, also known as the B biotype. Tomato is the predominant TYLCV host, perhaps due to its ubiquitous nature. It has been shown, however, that the TYLCV infection status of 
the host affects vector preference and that the relationship between TYLCV and its whitefly vector may be mutualistic, with the effect particularly benefitting the B. tabaci Mediterranean or Q biotype (Chen et al. 2013; Fang et al. 2013; Legarrea et al. 2015; Maluta et al. 2014; Pan et al. 2013). Several weeds, pepper (Capsicum annum), bean (Phaseolus vulgaris), and other plant species have also been reported as experimental or natural hosts for TYLCV (Morilla et al. 2005; Navas-Castillo et al. 1999; Polston et al. 2006, 2009; Smith et al. 2015), although the epidemiological significance of these nontomato hosts remains to be demonstrated.

Current management tactics focus on farm-centric strategies that rely mainly on the strategic application of insecticides for vector control, the use of TYLCV-resistant cultivars, rogueing infected plants, and various cultural controls, including metallic reflective mulch, staggered planting dates, and the prompt destruction or burn-down of fields after harvest to eliminate virus reservoirs (Riley and Srinivasan 2019; Schuster et al. 2008; Smith et al. 2019; Stansly et al. 2015). The effectiveness of these approaches-for controlling either whitefly or TYLCV-has arguably been limited. To some degree, this has been attributed to the absence of a coordinated effort to implement management strategies on a scale comparable with that of the target population (Smith et al. 2019). A single grower's field occupies an area that is considerably smaller than the area occupied by a breeding population of whitefly; we hypothesize that the targeted whitefly population spans multiple farms. Because farm managers often do not consult with one another when making pest-management decisions, asynchronous execution of control strategies among neighboring farms (e.g., insecticide application) is commonplace. This leads to only a portion of the pest population being treated at any given point in time and rapid reinfestation of the treated area by whiteflies from the surrounding, nontreated areas. Moreover, as populations are repeatedly exposed to the same insecticides during the production season, the development of insecticide resistance is accelerated. Indeed, resistance monitoring for neonicotinoids in Florida has shown that tolerance in B. tabaci biotype B (the primary biotype in Florida) increased 8-fold from 2000 to 2006 for imidacloprid and approximately 15-fold from 2003 to 2006 for thiamethoxam (Schuster et al. 2006). Resistance monitoring in 2014 confirmed high levels of imidacloprid and thiamethoxam resistance in some $B$. tabaci populations in southern Florida (Smith et al. 2016).

Areawide pest management (AWPM) — where the management unit is defined by the broad spatial boundaries of the pest, proven integrated pest management (IPM) practices are implemented, and management decisions are coordinated within this area-is hypothesized as a practical strategy that can maintain whitefly populations and associated plant viruses below damage and economic thresholds (Campbell et al. 2017; Faust 2008). Translating to commercial vegetable production, management units should be delimited by the intersection of the boundaries of the pest population and the commercial production fields to be managed. The boundaries of commercial production fields are reasonably simple to map. Mapping the pest population, on the other hand, requires large-scale and regular sampling to identify where and when the pests occur in the landscape to adequately characterize the spatial and temporal dynamics of the targeted populations.

A wide variety of statistical tools are available to characterize the spatial properties of a population over a defined area, as well as to describe how these properties change over time in response to a set of explanatory variables. Correlation analyses are commonly used to characterize spatial relationships. Polynomial distributed lag regression (PDR) is used for temporal analyses. PDR has only recently begun to be utilized in plant pathology studies (Carisse et al. 2013; Madden and Paul 2010; Paul et al.
2007), despite its previous use in other disciplines (e.g., econometrics and human epidemiology) (Batten and Thornton 1983; Schwartz 2000). A distributed lag model is essentially a regression equation used to predict the current value of a dependent variable based on both current and lagged values of one or more explanatory variables. The model assumes that the effects of the explanatory variables on the dependent variable are spread over time.

The objective of this study was to characterize the populations of whitefly and TYLCV in commercial tomato production in southwestern Florida and utilize this information as a means to predict whitefly density and TYLCV disease incidence as a function of environmental and geographical factors. An approach that utilizes the spatial and temporal information to foster the development of AWPM as a new strategy for managing TYLCV epidemics is presented.

\section{MATERIALS AND METHODS}

Survey region. A comprehensive map of vegetable fields in southwestern Florida's Collier, Hendry and Lee Counties (District 3 ) was developed in consultation with local scouts and University of Florida Extension personnel in spring and summer 2007 (Fig. 1). In general, field maps for individual farms were provided by the cooperating growers as hand-drawn maps. This information was transferred onto satellite imagery using Google Earth's drawing tools, and the final map was subsequently imported into ArcMap (ArcGIS ver. 10.2; Esri, Redlands, CA) to create a "shape" file. Approximately 82,000 acres of vegetable production in southwestern Florida were mapped, and scouting reports for approximately 17,000 to 20,000 acres of tomato production (Fig. 1, shaded areas) were collected each season over the duration of the study. The centroids for each field scouted were calculated, and the $x$ and $y$ coordinates were mean-centered and replotted to show the exact spatial coordinates (of the centroids) used in subsequent spatial calculations (Fig. 2). Fields ranged in size from 0.85 ha (minimum) to 83 ha (maximum) with $6.8,11.7$, and 17.6 ha being the first, second (median), and third quartiles, respectively. Only a small proportion of fields were much larger than 30 ha; the 95 th and 99 th percentiles were 33.4 and 56.1 ha, respectively. These larger fields were typically two or more fields but reported as one in the scouting reports.

Production information. In general, the information provided to us for most fields was the planting and harvest dates of the crop (normally tomato). Cultivar, fertilization regime, and pesticide-use information was not made available to us by all growers, nor was it necessarily requested once it was learned that such information was deemed proprietary by some cooperating growers. Nonetheless, in conversations with farm managers, it was indicated that, within any single operation, fields were managed similarly using standard commercial production practices as outlined by the University of Florida. Whitefly management was largely achieved through the regular and intensive application of insecticides. Management of TYLCV was a consequence of whitefly management or the use of resistant cultivars although, during the period of study, resistant cultivars were not widely planted in this region.

Disease and insect sampling. Tomato fields were sampled by private consulting firms according to proprietary methods to obtain estimates of disease incidence and whitefly density at the field scale. In general, for younger plantings, the number of whiteflies was counted on a select number of plants in selected areas. For older plantings, the number of whiteflies was counted on a select number of leaves on a select number of plants in selected areas. In both cases, TYLCV was rated as yes or no at the plant scale. Sampling reports were collected by the authors and disease incidences and whitefly densities were extracted and entered initially into an Excel worksheet and ultimately exported into ArcMap for spatial 
representation and analysis. Some but not all fields were sampled twice per week from planting through harvest. Thus, weekly data, derived either directly from a single sampling or calculated as the average of two samplings, were used to standardize the sampling data for analysis. Overall, analyses and model construction were based upon data collected from 865 fields, not all of which were planted or sampled in each season, operated by eight companies surveyed over 459 sampling dates spanning six production seasons. In District 3, the production season generally begins in late August and ends in May, spanning calendar years. Thus, to simplify presentation, production seasons will be numbered and referred to herein as production years (or simply years) 1 through 6 , where $1=2006-07,2=2007-08,3=$ $2008-09,4=2009-10,5=2010-11$, and $6=2011-12$. Within each production year, there were generally two production seasons, fall and winter (commonly referred to as spring in Florida). Planting in the fall season occurs from August through October, with peak harvest occurring from December through January; planting for the spring season occurs from November through February, with peak harvest occurring from mid-February through May.

General linear model analyses. Simple general linear model (GLM) analyses were used to determine how various temporal and spatial descriptors affected whitefly densities and TYLCV incidences over the study area. Two temporal factors were created from the data. First, the year factor was created to categorize the six production years (i.e., 1 to 6 ). Second, the season factor was created to categorize plantings into one of two production seasons: fall (August to October) or spring (November to February). Fields were also grouped into equal-area quadrants by simply identifying the latitude and longitudinal coordinates that bisected the survey region, then assigning fields to these quadrants based on their centroid positions. This was done for the entire data set, as well as for a subset of the data that included only the larger production region (it excluded two smaller regions) to provide a survey region that was generally contiguous (Fig. 2). Finally, area was used as a measure of the size of the production field. Area quartiles were determined and used to classify the fields by their area accordingly. For the analyses, the factors were considered only individually. Because this was not a designed experiment-where factors and levels are typically distributed evenly across treatments or replications-interaction terms were not evaluated because many interactions were nonestimable due to the unbalanced nature of the data across the variables.

A second GLM analysis was used to evaluate the effect of grower on mean TYLCV incidence and mean whitefly density. In total, eight different growers participated in the study. However, not all growers participated in each year of the study. Thus, to standardize the analysis, year 1 was omitted from the analysis because only one (large) grower organization was surveyed during the first year. This grower, however, was present in all subsequent years. Three other growers (numbers 2, 5, and 8) were also omitted. One of the three growers ceased operation at the end

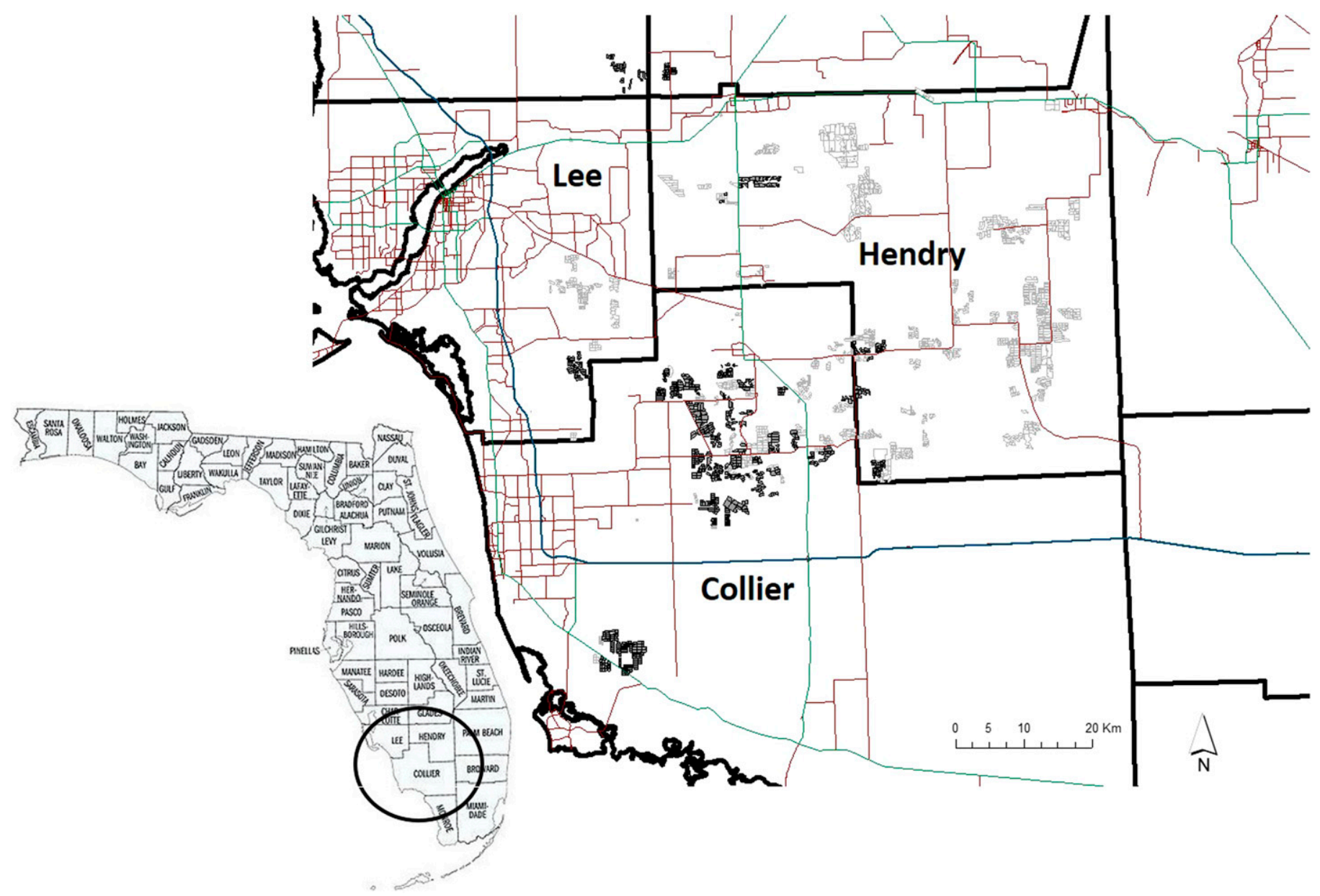

Fig. 1. Map of Florida showing location of the three-county (Collier, Hendry, and Lee) study area in the southwestern part of the state. Vegetable fields (lightand dark-shaded polygons) were identified by professional scouts and University Extension personnel using Google Earth images. This map is not a comprehensive representation of all vegetable fields in the region but, rather, an estimation based on expert knowledge of the region and the satellite imagery gathered in 2007 of likely locations of vegetable production (not exclusively tomato). Dark-shaded fields were those selected for sampling at least once during the 6-year study; not all were necessarily included in the analyses for a variety of reasons discussed in the text. Lightly shaded fields were not included in the study. 
of year 4, while the other two managed much smaller acreage. The factors considered in this model (as defined above) were grower (five growers), year (5 years), field area (classed by quartile), and the two-way interactions of year and area with grower.

For both GLM analyses, the logarithmic transformation was applied to mean whitefly density and the arcsin-square root transformation was applied to maximum TYLCV incidence prior to analysis. The GLIMMIX procedure of SAS (version 9.4; SAS, Cary, NC) was used to run the analyses.

Regression and correlation analyses. The spatial coordinates of the centroids for each field in the study area were determined with ArcMap. The distances between all possible field pairs were calculated based on The North American Datum of 1983 (with High Accuracy Reference Network [HARN]) Geographical Coordinate System; this was the default coordinate system used for our analyses. For each field, the mean and maximum whitefly density and the mean and maximum TYLCV incidence over the sampling period were calculated. For TYLCV, maximum values were typically the last value obtained during the season. This was expected. However, these values were sometimes uncharacteristically high relative to the mean, because growers would often stop insect management during the harvest period.

Nearest-neighbor analysis. Linear regression was used to define the relationship between whitefly density and TYLCV incidence for first-order nearest neighbors, where a first-order neighbor was any neighboring field that shared a border with the primary field. Because the borders of neighboring fields were not necessarily in contact, we created a buffer region of $250 \mathrm{~m}$ around each field, such that fields with overlapping buffer regions would be defined as neighbors. To stabilize the variance, logarithmic transformation was applied to both the independent and dependent variables. The factor "year" was added subsequently as a categorical variable to determine whether these relationships varied significantly among production years.

Correlation analysis. The Pearson product-moment correlation, Spearman rank-order correlation, and Kendall's tau-b coefficient were calculated to measure the degree of association among the four dependent variables (i.e., the mean and maximum whitefly densities and the mean and maximum TYLCV incidences) calculated for each field over a sampling season, in an effort to quantify TYLCV infection status and vector preference. Pearson's product-moment correlation is a parametric measure association between two variables, whereas Spearman's rank-order correlation and Kendall's tau-b are nonparametric measures of association that use the ranks of the data values or the number of concordances and discordances in paired observations, respectively. As above, the logarithmic transformation was applied to the whitefly variables and the arcsin-square root transformation was applied to the TYLCV variables prior to analysis. The CORR procedure of SAS (version 9.4; SAS) was used to run the analysis.

Moran's I. Spatial autocorrelation analysis was used to determine the spatial relationship of whitefly density and TYLCV incidence among fields located at various distances in the survey region. Analyses were conducted for three separate groupings of fields: fields planted in the fall season (August through October), fields planted in the spring season (November through February), and the complete data set. For each field in a given set, seasonal mean whitefly densities and TYLCV incidences were calculated and subsequently used in the autocorrelation analyses. Moran's $I$ (Chen 2013) was used as the measure of autocorrelation for all lag distances between 1 and 20 (noncumulative), where one lag distance was equal to either the first-quartile, median, mean, or third-quartile distance between all possible field pairs. The statistical significance of $I$ was assessed at each lag value by normal approximation using a $z$ score to test the hypotheses of $I$ being equal to zero. The Excel add-on 'Rookcase' was used for all calculations (Sawada 1999).

Weather data. Daily weather data for weather stations listed in Table 1 was obtained from the Florida Automated Weather Network (https://fawn.ifas.ufl.edu/) and the Global Historical Climatology Network (https://www.ncdc.noaa.gov/). Weather data for each field per year was spatially interpolated via universal kriging according to an isotropic exponential variogram, as detailed in Appendix 1. Examined weather variables included average, maximum, and minimum air temperature $\left(\mathrm{T}_{\mathrm{avg}}, \mathrm{T}_{\max }\right.$, and $\mathrm{T}_{\min }$, respectively, in degrees Celsius); precipitation ( $\mathrm{P}$, in millimeters); relative humidity ( $\mathrm{RH}$, in percent); vapor pressure deficit (VPD, in hectopascals); average and maximum wind speed $\left(\mathrm{W}_{\mathrm{avg}}\right.$ and $\mathrm{W}_{\max }$, respectively, measured at $10 \mathrm{~m}$ in kilometers per hour); and the indicator variables of $\mathrm{T}_{\mathrm{avg}}>25^{\circ} \mathrm{C}(\mathrm{Tgt} 25), 9>\mathrm{T}_{\mathrm{avg}}$ $>40^{\circ} \mathrm{C}$ (Tlt9gt40), $16 \leq \mathrm{T}_{\mathrm{avg}} \leq 24^{\circ} \mathrm{C}$ (T16to24), and $30 \leq \mathrm{RH}$ $\leq 60 \%$ (RH30to60). $\mathrm{T}_{\text {avg }}$ was calculated as $\left(\mathrm{T}_{\max }+\mathrm{T}_{\min }\right) / 2$, and VPD was calculated as $(1-\mathrm{RH} / 100) \times 6.11 \times \exp$ $\left[\left(17.47 \times \mathrm{T}_{\mathrm{avg}}\right) /\left(239+\mathrm{T}_{\mathrm{avg}}\right)\right]($ Buck 1981; Fourie et al. 2013; Rossi et al. 2009).

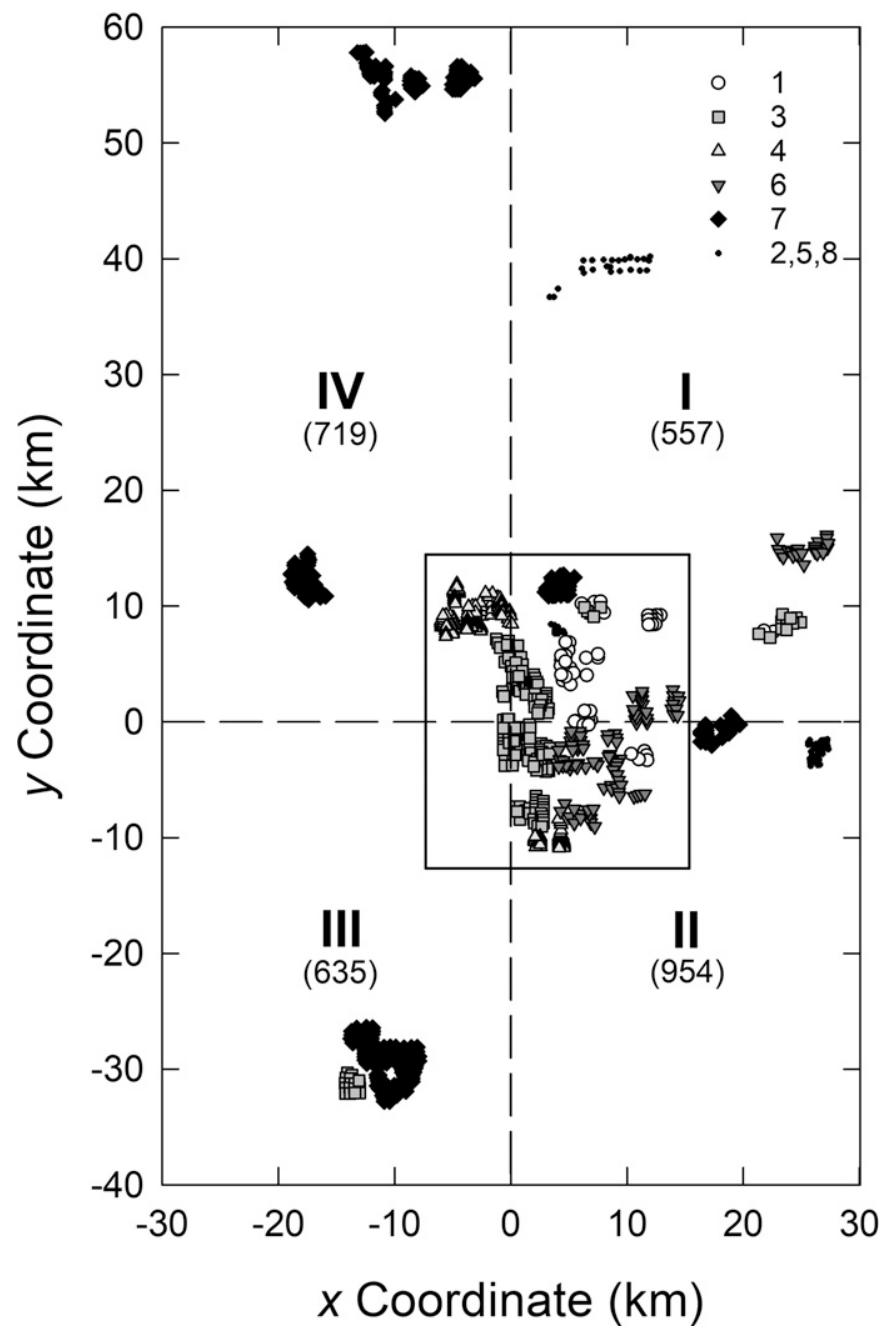

Fig. 2. Field centroid locations of all field samplings conducted over the course of the study. The $x$ and $y$ coordinates were centered by subtracting the mean value of the respective coordinate. The four quadrants (I to IV) used in the linear modeling analyses are shown and delineated by the dashed lines. The number of observations in a quadrant is shown in parentheses below the quadrant number. Data are further categorized by an anonymous grower number (1 to 8 ). Growers 2, 5, and 8 are deemphasized because they were not included in mixed-model analysis due to incomplete data (i.e., missing years) or a low number of observations. The subset dataset consists of the centroids enclosed by the inner rectangle. 
Polynomial distributed lag regression. The general approach to constructing and fitting polynomial distributed lag regression models was as described by Paul et al. (2007) and Madden and Paul (2010). Variations in whitefly densities (counts) and TYLCV incidences were separately described according to the following model:

$$
Y_{i j r t}=\alpha+\sum_{k=0}^{d} \eta_{k}^{(f)} Z_{(k) i j t}^{(f)}+G_{r}+T(L)_{i j}+e_{i j r t}
$$

in which $Y$ is the natural $\log$ (whitefly +0.01$)$ of field $i$, under grower $r$, in year $j$, at day $t ; \alpha$ is an intercept; $d$ is the polynomial degree of weather variable $f ; \eta_{k}$ is a component parameter of the $\beta$ parameter (see below) corresponding to weather variable $Z^{(f)}$ at degree $k$ ( $k=0$ to $d$ by 1 ) for field $i$, in year $j$, at day $t ; G_{r}$ is the random effect of grower $r$ (mean 0 , variance $s_{G r}{ }^{2}$ ); $T(L)_{i j}$ is the random effect of field $i$ within year $j$ (mean 0 , variance $s_{T(L)}^{2}$ ); and $e$ is a residual error term for field $i$, in year $j$, with grower $r$, at day $t$. Construction of $Z_{(k)}^{(f)}$ variables was performed in a SAS data step. Maximumlikelihood-based estimation within PROC GLIMMIX was used for model fitting. A first-order autoregressive residual covariance structure provided the best fit to the data, by way of lowest corrected Akaike Information Criterion (AICC), to the data.

Effects of weather variables were examined over time windows of 3 to 31 days. Polynomial degrees in the whitefly analysis were $d=0$ for $\mathrm{T}_{\mathrm{avg}}, \mathrm{T}_{\min }, \mathrm{Tgt} 25$, Tlt9gt40, T16to24, and RH30to60; and $d=1$ for $\mathrm{W}_{\max }, 2$ for $\mathrm{RH}$, and 3 for $\mathrm{W}_{\mathrm{avg}}, \mathrm{T}_{\max }, \mathrm{P}$, and VPD. Variables with different polynomial degrees in the TYLCV analysis than those in the whitefly analysis were $\mathrm{P}, d=1$; VPD and $\mathrm{W}_{\mathrm{avg}}, d=2$; and $\mathrm{T}_{\mathrm{avg}}$, $\mathrm{T}_{\min }, \mathrm{W}_{\max }$, and $\mathrm{RH}, d=3$. Following Paul et al. (2007), examination of weather variable combinations was limited to a maximum of three predictors. Variable combinations were controlled to prevent redundancy (i.e., multiple predictors corresponding to the same variable were not combined within one model). In total, 133 weather variable combinations were examined for each response. As in Madden and Paul (2010), $\beta$ parameters of weather variable $f$ at lag $m$ were defined according to the following equation:

$$
\beta_{Z^{(f)} m}=\sum_{k=0}^{d} \eta_{k}^{(f)} m^{k}
$$

The $\beta$ parameters represent the day-specific coefficients per distributed predictor variable that are of interest in the modeling, are constrained according to polynomial response surface functions to reduce effects of serial correlation, improve stability of estimated values and efficiency of the estimation process, and are estimated in the second stage of the analysis following modeling according to equation 1 (Madden and Paul 2010; Paul et al. 2007). Reliability of models in predicting observed values was measured with the concordance correlation coefficient (CCC) (Lin 1989, Madden et al. 2007).

Model evaluation. To evaluate parameter stability of the selected models, influential observation analysis was performed. Furthermore, model performance was evaluated using data partitioning approaches. Both procedures are detailed in Appendix 2.

\section{RESULTS}

Generally, whiteflies and TYLCV appeared in every season (Fig. 3). Whitefly numbers and TYLCV incidences increased across the landscape from the fall to spring crops. However, severe freeze events (for Florida) during the winters of 2009, 2010, and 2011 (i.e., during years 3 to 5) had significant impacts on both the whitefly population and the TYLCV tomato host. The spring crop was much more affected by these events. This is captured in the analyses below.

GLM analyses. The analyses showed that the two temporal factors (year and season) had the largest effects on TYLCV incidence and whitefly density in both the full and subset data sets (Table 2). The temporal factors were highly significant for TYLCV. Years 1, 2, and 6 had the highest average incidence of TYLCV, being significantly different from each other as well as being significantly different from years 3,4 , and 5 , which had very low and nearly equivalent levels of TYLCV (Table 3 ). Whitefly density was highest in years 1 and 2-corresponding to two of the years with high TYLCV incidence-followed, in general, by years 3 and 6 , and then years 4 and 5 (Table 3 ). The seasonal impact was consistent in that both TYLCV incidence and whitefly densities were always significantly higher in the spring season than the fall season for each production year (Table 3 ).

The two spatial factors-quadrant and area-generally had a lesser impact on TYLCV incidence and whitefly density than the temporal factors, with the exception of the quadrant effect on whitefly density in the subset data (Table 2). It should be noted that quadrant, though logically constructed (i.e., using the mean $x$ and $y$ coordinates to bisect the landscape) (Fig. 2), is an arbitrary division of the landscape done simply to determine whether TYLCV incidence or whitefly density changed across the landscape. It was reasoned that, if either of the response variables were randomly distributed across the landscape, then the factor would be statistically insignificant. Quadrants 1 and 4, the northernmost

\begin{tabular}{|c|c|c|c|c|c|}
\hline Station & Easting (m) & Northing (m) & Elevation (m) & Source $z$ & Date of operation \\
\hline Arcadia & 613,665 & 359,740 & 19.5 & FAWN & January 2006-December 2012 \\
\hline Clewiston & 692,597 & 307,277 & 5.8 & FAWN & November 2007-December 2012 \\
\hline Immokalee & 654,765 & 275,696 & 10.7 & FAWN & January 2006-December 2012 \\
\hline Palmdale & 666,164 & 327,300 & 11.6 & FAWN & January 2006-December 2012 \\
\hline Buckingham & 627,146 & 296,954 & 13.1 & GHCN & July 2008-July 2013 \\
\hline Big Corkscrew & 644,284 & 264,686 & 7.9 & GHCN & August 2007-June 2013 \\
\hline Big Cypress & 699,363 & 261,831 & 4.6 & GHCN & January 2006-July 2013 \\
\hline Devil's Garden & 685,362 & 292,031 & 6.1 & GHCN & January 2006-June 2013 \\
\hline Everglades & 661,244 & 207,747 & 1.5 & $\mathrm{GHCN}$ & January 2006-December 2012 \\
\hline Immokalee & 654,738 & 275,690 & 10.7 & GHCN & January 2006-July 2013 \\
\hline La Belle & 655,494 & 307,195 & 4.9 & GHCN & February 2008-July 2013 \\
\hline Marco Island & 628,595 & 218,230 & 3.0 & GHCN & January 2006-December 2012 \\
\hline Muse & 642,277 & 318,708 & 2.1 & GHCN & January 2006-July 2013 \\
\hline Naples & 627,954 & 242,571 & 1.5 & GHCN & January 2006-July 2013 \\
\hline Oasis RS & 696,896 & 209,819 & 2.4 & GHCN & January 2006-December 2012 \\
\hline Ortona Lock 2 & 667,487 & 312,326 & 6.1 & GHCN & January 2006-July 2013 \\
\hline Charlotte Corp. Airport & 599,100 & 325,179 & 7.6 & GHCN & January 2006-July 2013 \\
\hline Fort Myers Reg. Airport & 623,300 & 283,282 & 9.4 & GHCN & January 2006-July 2013 \\
\hline
\end{tabular}

TABLE 1. Regional weather stations used for interpolation of weather data

${ }^{\mathrm{z}}$ FAWN $=$ Florida Automated Weather Network and GHCN = Global Historical Climatology Network. 
quadrants, had the highest mean TYLCV incidence and whitefly density (Table 3). A fuller description of the spatial relationships of TYLCV incidence and whitefly density is given below with Moran's I analysis. The effect of area (i.e., field size) was inconsistent and did not follow an obvious pattern (Table 3).

There was a significant grower effect, with growers 1 and 4 having the highest level of TYLCV and whitefly over the course of the 6-year study (Table 4). The majority of these grower's fields existed within the subset region depicted in Figure 2 and, thus, were clustered geographically. The more isolated growers generally had less TYLCV and whitefly on average.

Regression and correlation analyses. Nearest-neighbor analysis. A strong linear relationship between the logarithms of TYLCV incidences as well as between the logarithms of whitefly densities for first-order neighbors was found (Table 5; Fig. 4). The slope values were slightly less than 1 , indicating a general decrease in TYLCV incidence or whitefly density in the neighboring fields. The year factor had a significant but small effect for both TYLCV and whitefly, largely indicating that the neighbor relationship was mostly stable among years.
Correlation analysis. The correlation matrix (Table 6) showed correlations $>0.8$ between the mean and maximum values of whitefly density and of TYLCV incidence for all three correlation statistics calculated $(\operatorname{Pr}<0.0001)$. Mean whitefly density was more strongly correlated than maximum whitefly density with mean TYLCV incidence and maximum TYLCV incidence $(\operatorname{Pr}<0.0001$ for all correlations). Correlations ranged between 0.41 and 0.57 , indicating moderately strong relationships between whitefly and TYLCV (as expected); however, a causal relationship cannot and should not be deduced from the analyses.

Moran's I. Correlograms were very similar in appearance and provided equivalent information regardless of the lag value chosen (i.e., first-, second- [= median], or third-quartile distances and average distance) (Table 7); correlograms presented here are based on third-quartile distances for the fall and spring crops (Figs. 5 and 6 , respectively). In all years, significant spatial autocorrelations were found for both TYLCV incidence and whitefly density. The sample sizes throughout this study were sufficiently large that most values of $I>0.15$ were significantly greater than 0 . The extent of the correlation varied among years.
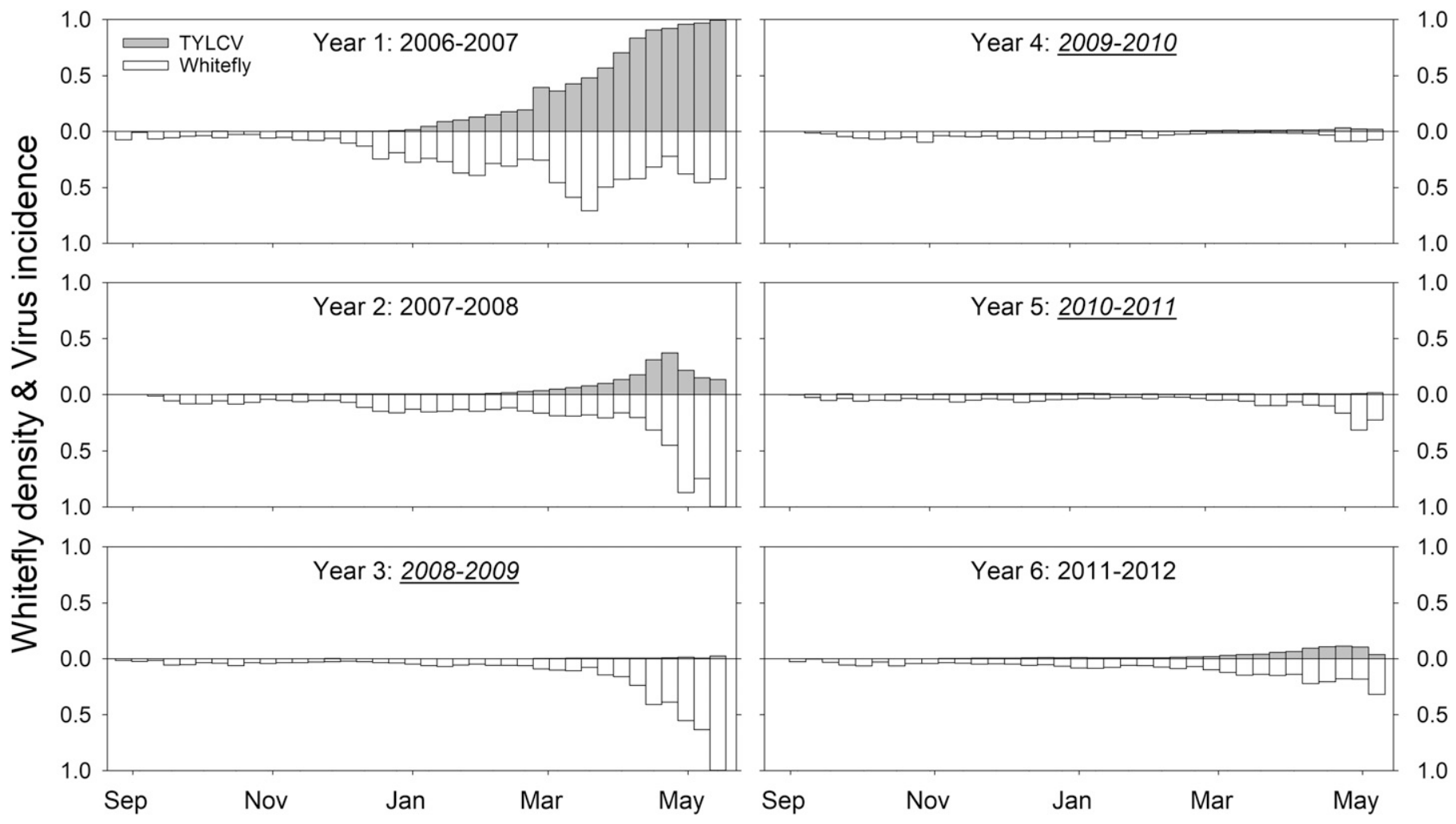

Fig. 3. Mean proportion of tomato yellow leaf curl virus (TYLCV)-infected plants (top panels, gray bars) and the mean number of whiteflies (bottom panels, white bars [scale inverted for purposes of presentation]) in all fields in production in the southwestern Florida study area at the specified time during the six production years studied. Production years that experienced significant freeze events during the winter are identified by an underlined and italicized title year.

TABLE 2. Results of a general linear modeling analysis of the effects of four variables on the means of tomato yellow leaf curl virus (TYLCV) incidence and number of whiteflies in commercial tomato fields in southwestern Florida over six production years ${ }^{\mathrm{z}}$

\begin{tabular}{|c|c|c|c|c|c|c|c|c|c|}
\hline \multirow[b]{3}{*}{ Effect } & \multirow[b]{3}{*}{ Levels } & \multicolumn{4}{|c|}{ TYLCV } & \multicolumn{4}{|c|}{ Whitefly } \\
\hline & & \multicolumn{2}{|c|}{ Full } & \multicolumn{2}{|c|}{ Subset } & \multicolumn{2}{|c|}{ Full } & \multicolumn{2}{|c|}{ Subset } \\
\hline & & $F$ value & $\operatorname{Pr}<F$ & $F$ value & $\operatorname{Pr}<F$ & $F$ value & $\operatorname{Pr}<F$ & $F$ value & $\operatorname{Pr}<F$ \\
\hline Season & 2 & 157.70 & $<0.001$ & 159.17 & $<0.001$ & 97.30 & $<0.001$ & 107.03 & $<0.001$ \\
\hline Quadrant & 4 & 61.29 & $<0.001$ & 11.03 & $<0.001$ & 109.71 & $<0.001$ & 106.26 & $<0.001$ \\
\hline Area & 4 & 9.02 & $<0.001$ & 3.63 & 0.013 & 2.78 & 0.0396 & 2.07 & 0.1019 \\
\hline
\end{tabular}

$\mathrm{z}$ Analyses were conducted on the full data set and on a subset of the data representing a geographically centralized collection of fields. Full $=$ the entire data set and Subset $=$ a smaller set of the full data set that excluded two smaller regions to provide a survey region that was more spatially contiguous. 
In years with higher TYLCV incidence (i.e., years 1, 2, and 6), values of Moran's I near 0.15 were found out to approximately 2 to $3 \mathrm{~km}$. This was evident in the fall season for year 1 (Fig. 5A) and the spring season in years 2 and 6 (Fig. 6C and K). Also, correlations

TABLE 3. Mean values of tomato yellow leaf curl virus (TYLCV) incidence and whitefly density in both the Full and Subset data sets averaged over the year, season, quadrant, or area effect ${ }^{\mathrm{y}}$

\begin{tabular}{|c|c|c|c|c|c|}
\hline \multirow[b]{2}{*}{ Effect } & \multirow[b]{2}{*}{ Value $^{\mathrm{z}}$} & \multicolumn{2}{|c|}{ TYLCV } & \multicolumn{2}{|c|}{ Whitefly } \\
\hline & & Full & Subset & Full & Subset \\
\hline \multirow[t]{6}{*}{ Year } & 1 & $0.3149 \mathrm{~A}$ & $0.3555 \mathrm{~A}$ & $0.1925 \mathrm{~A}$ & $0.2535 \mathrm{~A}$ \\
\hline & 2 & $0.1472 \mathrm{~B}$ & $0.1935 \mathrm{~B}$ & $0.1567 \mathrm{~B}$ & 0.1943 B \\
\hline & 6 & $0.1025 \mathrm{C}$ & $0.1403 \mathrm{C}$ & $0.0663 \mathrm{C}$ & $0.1075 \mathrm{D}$ \\
\hline & 5 & $0.0620 \mathrm{D}$ & $0.0834 \mathrm{D}$ & $0.0514 \mathrm{D}$ & $0.1031 \mathrm{D}$ \\
\hline & 4 & $0.0544 \mathrm{DE}$ & $0.0710 \mathrm{DE}$ & $0.0459 \mathrm{D}$ & $0.0885 \mathrm{E}$ \\
\hline & 3 & $0.0453 \mathrm{E}$ & $0.0590 \mathrm{E}$ & $0.0778 \mathrm{C}$ & $0.1286 \mathrm{C}$ \\
\hline \multirow[t]{2}{*}{ Season } & 2 & $0.1464 \mathrm{~A}$ & $0.1904 \mathrm{~A}$ & $0.1185 \mathrm{~A}$ & $0.1702 \mathrm{~A}$ \\
\hline & 1 & $0.0957 \mathrm{~B}$ & 0.1104 B & $0.0783 \mathrm{~B}$ & $0.1216 \mathrm{~B}$ \\
\hline \multirow[t]{4}{*}{ Quadrant } & 1 & $0.1397 \mathrm{~A}$ & $0.1706 \mathrm{~A}$ & $0.1436 \mathrm{~A}$ & $0.2492 \mathrm{~A}$ \\
\hline & 4 & $0.1476 \mathrm{~A}$ & $0.1686 \mathrm{~A}$ & $0.1179 \mathrm{~B}$ & $0.1337 \mathrm{~B}$ \\
\hline & 2 & $0.1241 \mathrm{~B}$ & $0.1335 \mathrm{~B}$ & $0.0968 \mathrm{C}$ & $0.1089 \mathrm{C}$ \\
\hline & 3 & $0.0728 \mathrm{C}$ & $0.1291 \mathrm{~B}$ & $0.0354 \mathrm{D}$ & $0.0918 \mathrm{D}$ \\
\hline \multirow[t]{4}{*}{ Area } & 1 & $0.1368 \mathrm{~A}$ & $0.1630 \mathrm{~A}$ & $0.0959 \mathrm{AB}$ & 0.1417 B \\
\hline & 2 & $0.1251 \mathrm{~B}$ & $0.1573 \mathrm{AB}$ & 0.1016 A & $0.1453 \mathrm{AB}$ \\
\hline & 3 & $0.1114 \mathrm{C}$ & $0.1397 \mathrm{C}$ & $0.0905 \mathrm{~B}$ & 0.1413 B \\
\hline & 4 & $0.1110 \mathrm{C}$ & $0.1416 \mathrm{BC}$ & $0.1058 \mathrm{~A}$ & $0.1552 \mathrm{~A}$ \\
\hline
\end{tabular}

y Full $=$ the entire data set and Subset $=$ a smaller set of the full data set that excluded two smaller regions in an effort to provide a survey region that was generally contiguous. Mean separation tests were applied to each factor individually on the transformed values but actual values are shown in the table. Tests were conducted using the SAS procedure GLIMMIX and invoking the LSMEANS/LINES command. For each factor, values sharing the same letter are statistically equivalent $(P=0.05)$.

$\mathrm{z}$ The year factor categorized the six production years (i.e., 1 to 6 ). The season factor categorized plantings into one of two production seasons based on planting date: fall (August to October $=1$ ) or spring (November to February $=$ 2). Fields were grouped into equal-area quadrants by bisecting the latitude and longitudinal coordinates of the survey region, then assigning fields to these quadrants based on their centroid positions. The area of a production field was considered by determining the quartiles in the collection of field areas, and subsequently classifying fields by their area accordingly.

TABLE 4. Mean values and associated standard errors (SE) for tomato yellow leaf curl virus (TYLCV) incidence and whitefly density by grower $^{2}$

\begin{tabular}{|c|c|c|c|c|}
\hline \multirow[b]{2}{*}{ Grower } & \multicolumn{2}{|c|}{ TYLCV } & \multicolumn{2}{|c|}{ Whitefly } \\
\hline & Mean & SE & Mean & SE \\
\hline 4 & 0.1356 & $0.0053 \mathrm{~A}$ & 0.0966 & $0.0068 \mathrm{~B}$ \\
\hline 1 & 0.1153 & $0.0080 \mathrm{~B}$ & 0.2475 & $0.0104 \mathrm{~A}$ \\
\hline 6 & 0.0929 & $0.0048 \mathrm{C}$ & 0.0628 & $0.0062 \mathrm{C}$ \\
\hline 3 & 0.0760 & $0.0028 \mathrm{D}$ & 0.0745 & $0.0037 \mathrm{C}$ \\
\hline 7 & 0.0379 & $0.0027 \mathrm{E}$ & 0.0454 & $0.0035 \mathrm{D}$ \\
\hline
\end{tabular}

z Mean separation tests were conducted using the SAS procedure GLIMMIX and invoking the LSMEANS/LINES command. Values sharing the same letter are statistically equivalent $(P=0.05)$. showed a pattern of decreasing in value with increasing lag distance during these years, indicating that TYLCV incidence was similar in neighboring fields and became less so with distance. This relationship also was evident with the whitefly population during those same years.

In years with low TYLCV incidence, values of Moran's $I$ tended to be lower than 0.15 for most lag distances, with the exception of peaks at the first three to four lag distances, indicating small clusters of TYLCV (Fig. 5G and I). In those same years, values of Moran's I
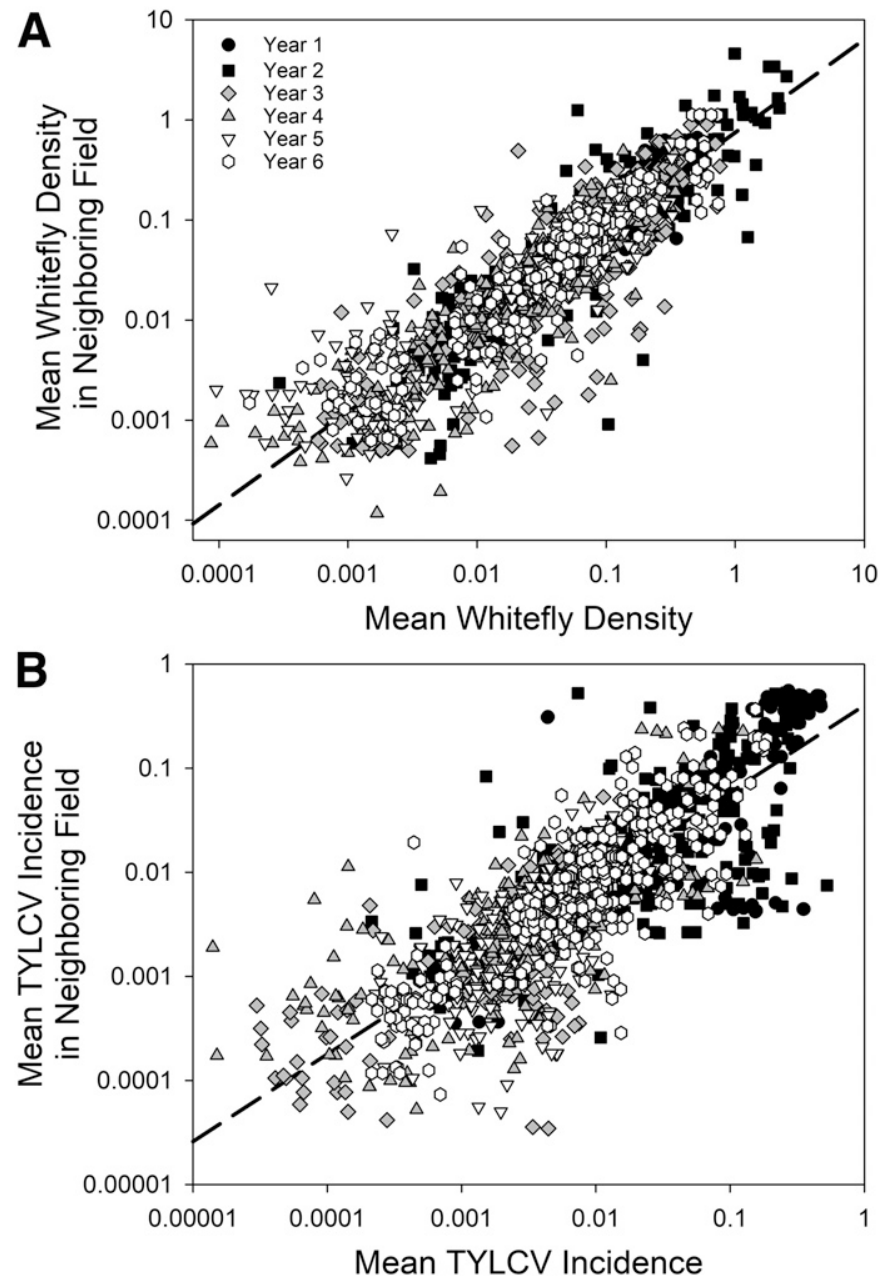

Fig. 4. The relationship between the logarithms (base 10) of the A, mean number of whiteflies in neighboring fields and $\mathbf{B}$, mean incidence of tomato yellow leaf curl virus (TYLCV)-infected plants in neighboring fields. A field was defined as a "neighboring field" if their nearest borders were within $500 \mathrm{~m}$. Symbols further categorize the observations by production season (1 to 6$)$.

TABLE 5. First-order nearest-neighbor analysis for tomato yellow leaf curl virus (TYLCV) incidence and whitefly density

\begin{tabular}{|c|c|c|c|c|c|c|c|c|}
\hline \multirow[b]{2}{*}{ Parameter } & \multicolumn{4}{|c|}{ TYLCV } & \multicolumn{4}{|c|}{ Whitefly } \\
\hline & Estimate & SE & $t$ Value & $\operatorname{Pr}$ & Estimate & SE & $t$ Value & $\operatorname{Pr}$ \\
\hline Intercept & -0.4010 & 0.0373 & -10.74 & $<0.001$ & -0.0827 & 0.0120 & -10.12 & $<0.001$ \\
\hline Slope & 0.8119 & 0.0131 & 61.98 & $<0.001$ & 0.9224 & 0.0080 & 110.50 & $<0.001$ \\
\hline 2 & 0.0167 & 0.0378 & 0.44 & 0.658 & -0.0320 & 0.0270 & -1.18 & 0.237 \\
\hline 3 & -0.0652 & 0.0410 & -1.59 & 0.111 & -0.0880 & 0.0275 & -3.21 & 0.001 \\
\hline 4 & -0.0779 & 0.0412 & -1.89 & 0.059 & -0.0754 & 0.0284 & -2.66 & 0.008 \\
\hline
\end{tabular}

y Adjusted $R^{2}$ values are $70.34 \%$ for TYLCV and $82.53 \%$ for whitefly.

$\mathrm{z}$ The estimate for year 1 was obtained by summing the intercept and slope values in each of the equations. For all other years, the year estimate was added to the intercept value. 
for whitefly showed an undulating pattern of higher values $(>0.15)$ for the fall season (before the freeze events) (Fig. 5F, H, and J), followed by lower values in the spring season (Fig. 6F, H, and $\mathrm{J}$ ), with values $>0.15$ typically extending approximately 3 to $5 \mathrm{~km}$. The high singular peaks evident with TYLCV were less prominent for whitefly, an indication that whitefly populations had a greater spatial extent than TYLCV. This makes sense given that the whitefly has a much broader host range than TYLCV. It should be noted that Moran's $I$ is a measure of the similarity of a collection of values relative to their distances and not a direct measure of the magnitude of the values. In other words, high correlation can exist when all values are near zero, so long as similar values are separated by approximately the same lag distance (Fig. 5E, F, and H).

Polynomial distributed lag regression. The best-fitting model for predicting the logarithm of whitefly counts was model 57 (Table 8), which included T16to24, RH, and VPD. Temperature between the optimal range for whitefly development (T16to24) was associated with increased whitefly counts. The polynomial degree of 0 for the coefficients of T16to24 indicated how the effect of this variable was consistent over a 31-day window (Fig. 7A). Higher RH values were associated with lower whitefly counts. One possible explanation for this is that $\mathrm{RH}$ values above $60 \%$ are suboptimal for whitefly development (Picó et al. 1996), and this effect being stronger on previous days would allow it to have a greater effect over multiple generations of whitefly (Fig. 7B). Greater VPD values were also associated with greater whitefly density. The effect of VPD was strongest on the current day and became weaker as the lag period increased toward an 8-day window (Fig. 7C). Model 57 predicted $\log$ whitefly with a reliability $(\mathrm{CCC})$ of 0.70 . The model tended to overpredict in the fall season and underpredict during

TABLE 6. Correlation statistics between the mean and maximum values of tomato yellow leaf curl virus (TYLCV) incidences and mean and maximum numbers of whiteflies in commercial tomato fields in southwestern Florida over six production years $(2006 \text { to } 2012)^{\mathrm{z}}$

\begin{tabular}{llllll}
\hline & \multicolumn{2}{c}{ TYLCV } & & \multicolumn{2}{c}{ Whitefly } \\
\cline { 2 - 3 } \cline { 5 - 6 } Analyses & Mean & Maximum & & Mean & Maximum \\
\hline TYLCV mean & & & & & \\
$\quad$ Pearson & 1 & 0.9608 & & 0.4532 & 0.3699 \\
$\quad$ Spearman & 1 & 0.9280 & & 0.5615 & 0.4941 \\
$\quad$ Kendall tau-b & 1 & 0.8158 & & 0.4100 & 0.3482 \\
TYLCV maximum & & & & & \\
$\quad$ Pearson & 0.9608 & 1 & & 0.4662 & 0.3815 \\
$\quad$ Spearman & 0.9280 & 1 & & 0.05672 & 0.4941 \\
$\quad$ Kendall tau-b & 0.8158 & 1 & & 0.4241 & 0.3646 \\
Whitefly mean & & & & \\
$\quad$ Pearson & 0.4532 & 0.4662 & & 1 & 0.9023 \\
$\quad$ Spearman & 0.5615 & 0.5672 & & 1 & 0.9374 \\
$\quad$ Kendall tau-b & 0.4100 & 0.4241 & & 1 & 0.8042 \\
Whitefly maximum & & & & & \\
$\quad$ Pearson & 0.3699 & 0.3815 & & 0.9023 & 1 \\
$\quad$ Spearman & 0.4831 & 0.4941 & & 0.9372 & 1 \\
$\quad$ Kendall tau-b & 0.3482 & 0.3646 & 0.8042 & 1 \\
\hline
\end{tabular}

$\mathrm{z}$ Analyses were conducted on the full data set. spring (Fig. 8A). Although the other models in Table 8 had CCC values similar to those of model 57 , the resulting weight ratios strongly supported model 57 as the best.

The model with the lowest AICC value for predicting log TYLCV incidence was model 59 (Table 9), which included T16to24, RH, and $\mathrm{W}_{\max }$. Temperature between the optimal range for whitefly development (T16to24) was associated with increased TYLCV incidence. Similar to the whitefly model, a polynomial degree of 0 for the coefficients of T16to24 showed the consistency of this effect over the 31-day window (Fig. 7D). Higher RH levels were associated with lower TYLCV disease incidence, with this effect being strongest over a 31-day window (Fig. 7E). The polynomial degree for $\mathrm{W}_{\max }$ was 3 , and the corresponding $\beta$ response surface related how increases in $\mathrm{W}_{\max }$ over 15- to 31-day windows were associated with decreases in TYLCV incidence, whereas greater $\mathrm{W}_{\text {max }}$ values during a 14-day window were associated with increases in TYLCV incidence (Fig. 7C). Reliability (CCC) of model 59 in predicted log TYLCV incidence was 0.72 (Fig. 8B). However, the model tended to underpredict TYLCV at high incidence values; this is evident by noting the underpredictions during April and May, when TYLCV was at its highest (Fig. 8B). The highest values were associated with the incidence values in year 1, when TYLCV was exceptionally high. Although the other models in Table 9 had CCC values similar to those of model 59, the resulting weight ratios strongly supported model 59 as the best.

An approach to AWPM. Whitefly and TYLCV pressure were mapped by dividing the $6,000-\mathrm{km}^{2}$ survey area into $100-\mathrm{km}^{2}$ cells, plotting the centroids as in Figure 2 such that centroid symbols were generated to represent whether whitefly, TYLCV, or both exceeded threshold (Fig. 9). A typical density threshold for whitefly was 0.1 and for TYLCV was $0.5 \%$. Further, centroid symbols that indicated that either the whitefly or TYLCV threshold was exceeded were scaled to a diameter of $6 \mathrm{~km}$; this represents twice the distance of TYLCV extent revealed in the Moran's $I$ analysis. The mapped data shows that both whitefly and TYLCV exceeded threshold (on average) within the central region of fields starting in the spring of year 1 and running in to both production seasons in year 2 (Note: year 1 data was the smallest data set collected). Subsequent years and seasons, however, showed an overall reduction in dual risk. This could be attributed to the drenching rains of tropical storm Faye in the fall of year 3 and hard freezes in the spring (January) in years 3 , 4, and 5 (Fig. 9, highlighted maps). These were the same weather events that affected the development of squash vein yellowing virus epidemics detailed by Turechek et al. (2014).

\section{DISCUSSION}

TYLCV and whitefly continue to be major and costly impediments to tomato production in Florida, the southeastern United States, and many other production regions worldwide. Management strategies that focus on vector control have proven to be only moderately effective in preventing TYLCV outbreaks. This is disappointing to commercial growers because, in the absence of resistant cultivars, there are seemingly no tangible alternatives for

TABLE 7. Yearly means for tomato yellow leaf curl virus (TYLCV) incidence and whitefly density over the entire study area ${ }^{z}$

\begin{tabular}{|c|c|c|c|c|c|c|c|c|c|}
\hline \multirow[b]{2}{*}{ Year } & \multicolumn{2}{|c|}{ Mean } & \multicolumn{7}{|c|}{ Neighbor distance statistics } \\
\hline & TYLCV & Whitefly & Min & $1 \mathrm{Q}$ & Median & Average & $3 Q$ & Max & Number \\
\hline 1 & 0.1521 & 0.2197 & 165 & 262 & 302 & 327 & 372 & 889 & 61 \\
\hline 2 & 0.0424 & 0.2018 & 129 & 232 & 288 & 324 & 378 & 1883 & 248 \\
\hline 3 & 0.0037 & 0.0876 & 129 & 232 & 280 & 325 & 367 & 2116 & 222 \\
\hline 4 & 0.0064 & 0.0471 & 129 & 235 & 287 & 330 & 383 & 4174 & 210 \\
\hline 5 & 0.0059 & 0.0491 & 129 & 234 & 287 & 320 & 385 & 1757 & 190 \\
\hline 6 & 0.0178 & 0.0737 & 95 & 229 & 278 & 305 & 352 & 891 & 171 \\
\hline
\end{tabular}

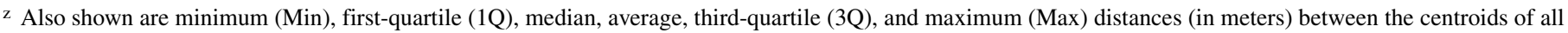
neighboring fields analyzed each year. Number indicates the number of neighboring fields per year included in each analyses. 
disease management. However, the landscape-scale data of TYLCV epidemics collected over 6 years and the subsequent analysis of the spatial and temporal extents of TYLCV and its whitefly vector has provided new information that can be used to develop a different approach to management.

Results from this study support the hypothesis that TYLCV epidemics are governed by whitefly populations and virus distributions that extend over geographical areas larger than a standard production field. Because these populations occupy such large areas, it is reasonable to assume that management strategies must also be carried out on an equivalent scale to be effective. The latter notion was not tested here but, rather, we attempted to identify the extent to which populations of whitefly and TYLCV exist over the agricultural landscape of southwestern
TYLCV

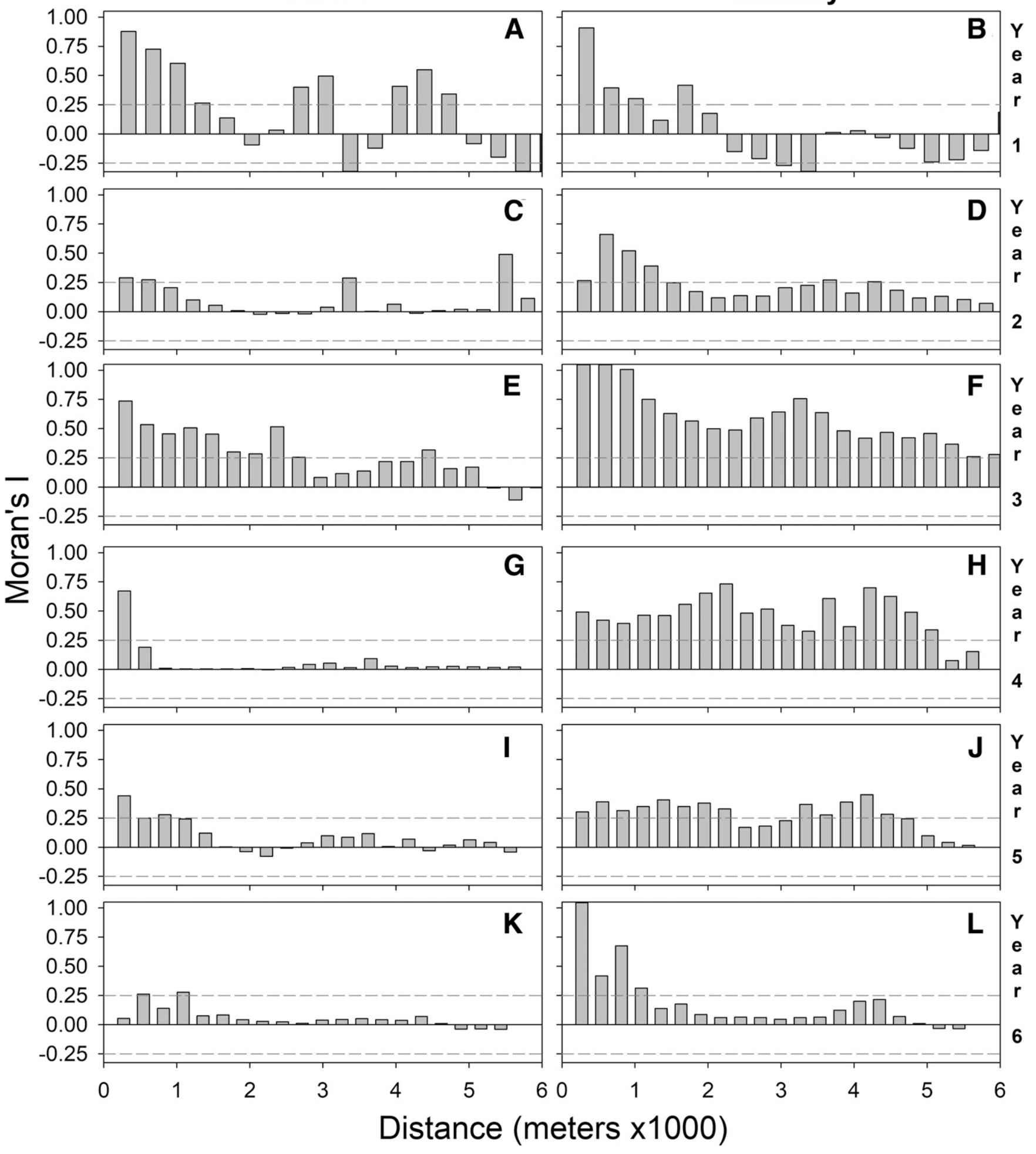

Fig. 5. Moran's $I$ for fall-planted fields in production years 1 through 6 for A, C, E, G, I, and $\mathbf{K}$, incidence of tomato yellow leaf curl virus (TYLCV)-infected plants and $\mathbf{B}, \mathbf{D}, \mathbf{F}, \mathbf{H}, \mathbf{J}$, and $\mathbf{L}$, whitefly number for lag distances up to $6 \mathrm{~km}$. Individual lags are based on the third-quartile distance calculated in each production year. 
Florida to develop guidelines to implement such a strategy. Although it is difficult to gain a complete understanding of the spatial and temporal dynamics that govern epidemic development due to the variability of production practices over a large geographical region, it is possible to obtain a general understanding of the factors that affect the scope of the populations and gather simple landscape-level statistics to facilitate efforts toward coordinated pest management.

First, the nearest-neighbor analysis indicated strong spatial correlations of whitefly densities and TYLCV incidences in neighboring fields (Fig. 4), and the analyses with Moran's I further defined these correlations over greater distances (Figs. 5 and 6). A
TYLCV

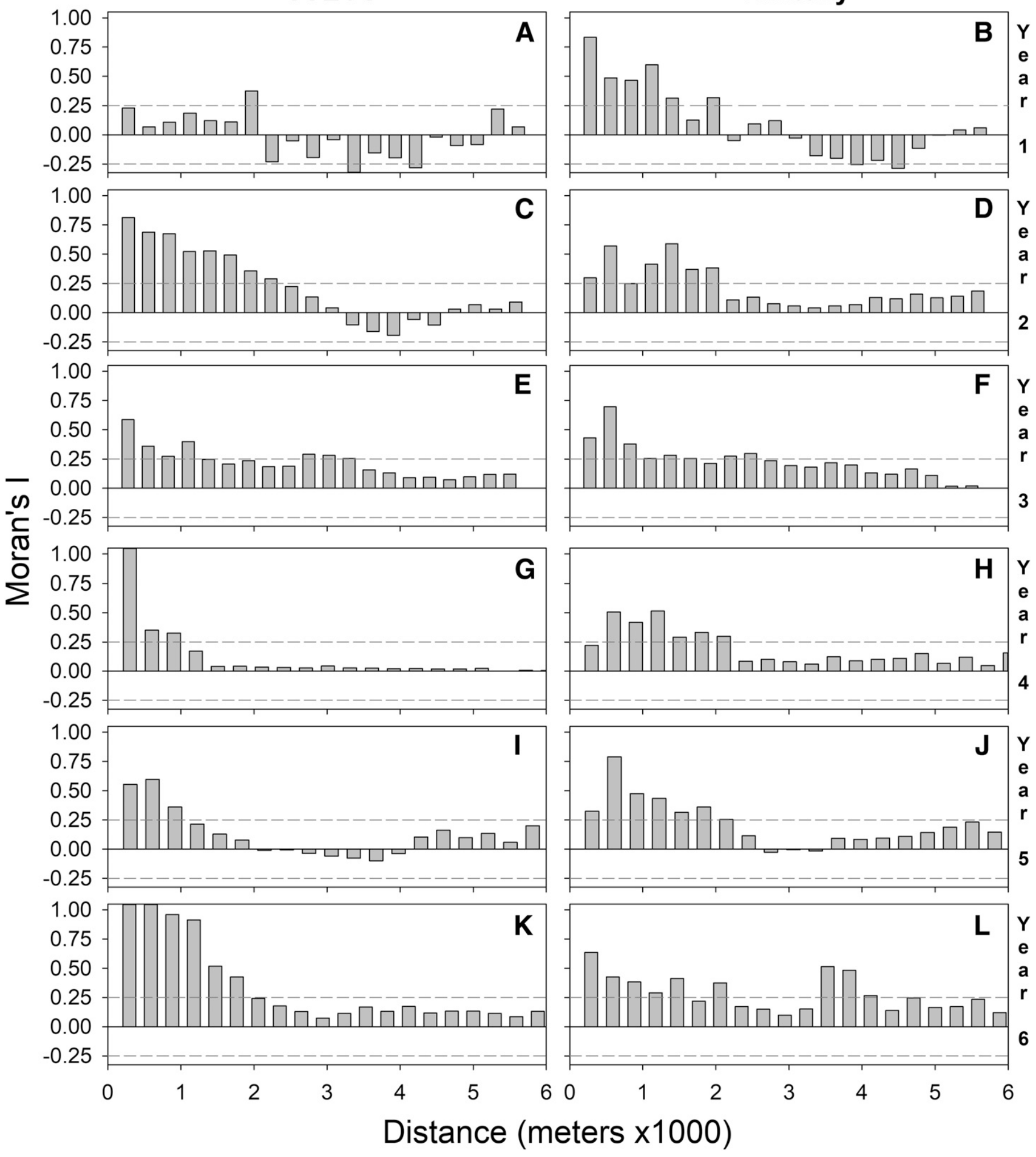

Fig. 6. Moran's I for spring-planted fields in production years 1 through 6 for A, C, E, G, I, and $\mathbf{K}$, incidence of tomato yellow leaf curl virus (TYLCV)-infected plants and $\mathbf{B}, \mathbf{D}, \mathbf{F}, \mathbf{H}, \mathbf{J}$, and $\mathbf{L}$, whitefly number for lag distances up to $6 \mathrm{~km}$. Individual lags are based on the third-quartile distance calculated in each production year. 
few factors may explain these correlations. To start, the crop is planted nearly contiguously over the production region, with planting dates being staggered to allow a steady harvest over the production season once the first-planted crop reaches maturity. The overlap in both time and space of old crops and new crops greatly facilitates a whitefly's search for a new host plant when its habitat is disrupted by actions such as insecticide spraying, harvesting, and crop burndown (i.e., an herbicide application applied after harvest). These activities often cause a whitefly to take flight and search for a new host plant. More importantly, these disruptive activities typically occur at the field scale, nearly ensuring that the disrupted whitefly population must locate new fields, which often are its nearest neighbors.

Second, it was clear that TYLCV epidemics were affected by the number and duration of winter freeze events. This observation is in line with that described for the whitefly-transmitted squash vein yellowing virus in watermelon (Turechek et al. 2014). In essence, TYLCV incidence was markedly lower after the occurrence of a significant freeze event due to reductions in the tomato plant hosts or whitefly populations. Following a significant freeze, the reduction in TYLCV lasted through the duration of the spring cropping season and into the following fall season. What constitutes a "significant" freeze is not well defined but the temperatures experienced during the winters of the 2009, 2010, and 2011 growing seasons were apparently sufficient to affect TYLCV development for several months following the freeze events, and even bridged the gap between the spring and fall crops when the whitefly population typically grows ahead of the fall crop.

Quantitative relationships that describe the reduction in TYLCV as a function of weather-related factors such as temperature are mostly undefined (but see Pusag et al. [2012]). However, several studies have examined the effect of temperature on whitefly adult, nymph, or egg mortality (Lin et al. 2007; Simmons and Elsey 1995; Xiao et al. 2016), with Simmons and Elsey (1995) and Lin et al. (2007) looking more closely at the effect of subfreezing temperatures. Simmons and Elsey (1995) showed that $3 \mathrm{~h}$ at $-6^{\circ} \mathrm{C}$ was needed to kill $90 \%$ of whitefly adults, and that $57 \mathrm{~h}$ at this temperature was needed to kill whitefly nymphs. At that approximate temperature, Lin et al. (2007) reported approximately $50 \%$ mortality of both adults and nymphs after $10 \mathrm{~h}$ of exposure (the longest duration in their study) but achieved $100 \%$ kill of adults after $10 \mathrm{~h}$ at $-10^{\circ} \mathrm{C}$, and nearly $90 \%$ kill of the nymphs. The differences in cold tolerance seen in these two studies could be a reflection of the different populations of whiteflies (southern United States versus northern China) or may be due to differences in the experimental design or procedures.

Among the six different variables examined that represented temperature, the indicator variables T16to24 or Tgt 25 were consistently present in the top temporal models predicting whiteflies or TYLCV and, consequently, contributed to better

TABLE 8. Top five linear mixed models with fit statistics for predicting the logarithm of the daily whitefly density

\begin{tabular}{lcccc}
\hline Model $^{\mathrm{x}}$ & AICC $^{\mathrm{y}}$ & $\mathrm{CCC}^{\mathrm{z}}$ & Model weight & Weight ratio \\
\hline 57: T16to24, RH, VPD & $272,211.1$ & 0.7013 & 1 & $\ldots$ \\
23: Tgt25, RH, VPD & $273,455.2$ & 0.6976 & $7.03 \times 10^{-271}$ & $1.42 \times 10^{270}$ \\
20: Tgt25, P, VPD & $273,490.5$ & 0.6977 & $1.52 \times 10^{-278}$ & $6.58 \times 10^{277}$ \\
54: T16to24, P, VPD & $273,604.8$ & 0.6959 & $2.30 \times 10^{-303}$ & $4.35 \times 10^{302}$ \\
27: Tgt25, VPD, W & $273,904.5$ & 0.6956 & 0 & $\ldots$ \\
\hline
\end{tabular}

${ }^{\mathrm{x}}$ Model variables correspond to temperature between 16 and $24^{\circ} \mathrm{C}$ (T16to24), temperature greater than $25^{\circ} \mathrm{C}(\mathrm{Tgt} 25)$, relative humidity ( $\left.\mathrm{RH}\right)$, vapor pressure deficit (VPD), total precipitation $(\mathrm{P})$, maximum wind speed $\left(\mathrm{W}_{\max }\right)$, and average wind speed $\left(\mathrm{W}_{\mathrm{avg}}\right)$. Variables were distributed over 8 days (VPD, $\mathrm{W}_{\mathrm{avg}}$, and $\mathrm{W}_{\max }$ ) or 31 days (T16to24, RH, and Tgt25). Polynomial order was $d=0$ for T16to24 and Tgt25, $d=1$ for $\mathrm{W}_{\max }, d=2$ for RH, and $d=3$ for $\mathrm{VPD}, \mathrm{P}$, and $\mathrm{W}_{\mathrm{avg}}$.

y Corrected Akaike Information Criterion.

z Concordance correlation coefficient. model performance than variables assuming more flexible response surfaces. Temperatures ranging between 16 and $24^{\circ} \mathrm{C}$ have been reported to be favorable overall for development of B. tabaci (Picó et al. 1996), though other studies have found that higher constant temperatures near 30 to $33^{\circ} \mathrm{C}$ correspond to shorter developmental times (Butler et al. 1983; Muñiz and Nombela 2001). Thus, the stable effect (polynomial degree $d=0$ ) of T16to24 over a 31-day window for the whitefly and TYLCV models is not entirely unexpected (Supplementary Tables S1 and S2).

When considering the T16to24 indicator variable itself, a day was assigned the value of 1 if its average temperature was within the range of 16 to $24^{\circ} \mathrm{C}$; days with average temperatures outside this range were assigned a 0 . Consequently, a static effect of T16to24 over multiple preceding days was indicative of this air temperature range having a net positive associated effect on whitefly density, as well as subsequent TYLCV incidence. Along these lines, a polynomial order other than zero for an indicator variable would place more emphasis on the day itself rather than the corresponding values of the environmental indicator variable. The $\beta$ parameters corresponding to the continuous temperature variable $\mathrm{T}_{\text {max }}$, on the other hand, exhibited a cubic response surface over preceding time windows and reflected how the contribution of maximum air temperature of an individual day in predicting whitefly density and TYLCV incidence varied with lag length. $T_{\max }$, however, was not present within the top models and, as such, its $\beta$ parameters were not estimated. RH between 30 and $60 \%$ has also been reported as optimal for $B$. tabaci development, with values lower or greater than this range detrimental to whitefly oviposition and survival (Gerling et al. 1986; Picó et al. 1996). It is also plausible that the zero-order polynomial response of T16to24 additionally reflects an interaction where less optimal temperatures coincide with more favorable RH conditions, or vice versa, leading to an averaging effect that appears constant (Paul et al. 2007).

Although there are many approaches that can be used to model responses as a function of environmental conditions (Littell et al. 2006; Madden et al. 2007; Schabenberger and Pierce 2002), this study specifically utilized polynomial distributed-lag mixed regression for several reasons. The salient points of this are that it provided a formal framework to facilitate evaluating effect distributions over varying time lags per variable, the polynomial $\beta$ parameter constraints provided an effective means to handle serially correlated weather and response data while concurrently contributing to stability of $\beta$ parameter estimation (which, without similar constraints, could have readily led to instability and nonparsimonious overfitting) and identification of predictor weights per day within each lag window, and it allowed for collective analyses of datasets across location-year groups while also accounting for correlations within those groups (Madden and Paul 2010; Paul et al. 2007; Schwartz 2000; Teklehaimanot et al. 2004). More than 100 models were tested for each of the dependent variables, and the top-performing models for each provided nearly identical predictions.

When more than one model exists, $\mathrm{Hu}$ et al. (2015) advocates combining models for improved prediction, and this was investigated for predictions of whitefly and TYLCV. Resulting CCC values from the top models for whitefly numbers (model 57) and for TYLCV incidence (model 59) were compared with those from the combination of the top two models per each response (model 23 was the second best performing model in both cases). In the current study, predictions from these model combinations did not exhibit improved CCC values (data not shown) compared with the respective individual top models.

This research was motivated by the general failure of current management practices to keep whitefly populations in check, thus leading to severe outbreaks of TYLCV. Results obtained here suggest that moving toward an AWPM strategy for the vector and virus is a seemingly prudent endeavor based on the spatial and temporal characteristics of both the whitefly and 
TYLCV. Ideally, use of the spatial and temporal models should be integrated with current action thresholds and used to support a risk-predictive approach to managing TYLCV epidemics; that is, the level of predicted whitefly or TYLCV that triggers a management action. In commercial production, that management action is likely to be an insecticide spray. The $6,000-\mathrm{km}^{2}$ grid could conceivably be considered the designated area for AWPM, with fields being assigned to the $10-\mathrm{km}^{2}$ cells based on their centroid location. When a field is classified as exceeding the whitefly or TYLCV threshold, the centroid expands to $6 \mathrm{~km}^{2}$ and all fields that exist within the cells intersected by the $6-\mathrm{km}^{2}$-radius fields would be designated to implement an agreedupon management action.
Mapping pest and disease pressure effectively highlights the risk areas within the landscape or management area (Fig. 9). In this instance, seasonal mean whitefly density and maximum TYLCV incidence were mapped. The seasonal information alone is likely not sufficient to guide weekly spray programs; however, that information is useful for assigning regional pre- or midseason risk levels that are partly predictable by weather events. In practice, maps such as these can be developed in near real time and need not be limited to "snapshots" in time. The spatial and temporal knowledge allow for an accurate portrayal of the risk areas which, when mapped, could form the foundation of an areawide approach for management of TYLCV epidemics. Unfortunately, maps alone are not enough to implement AWPM; however, they do help to

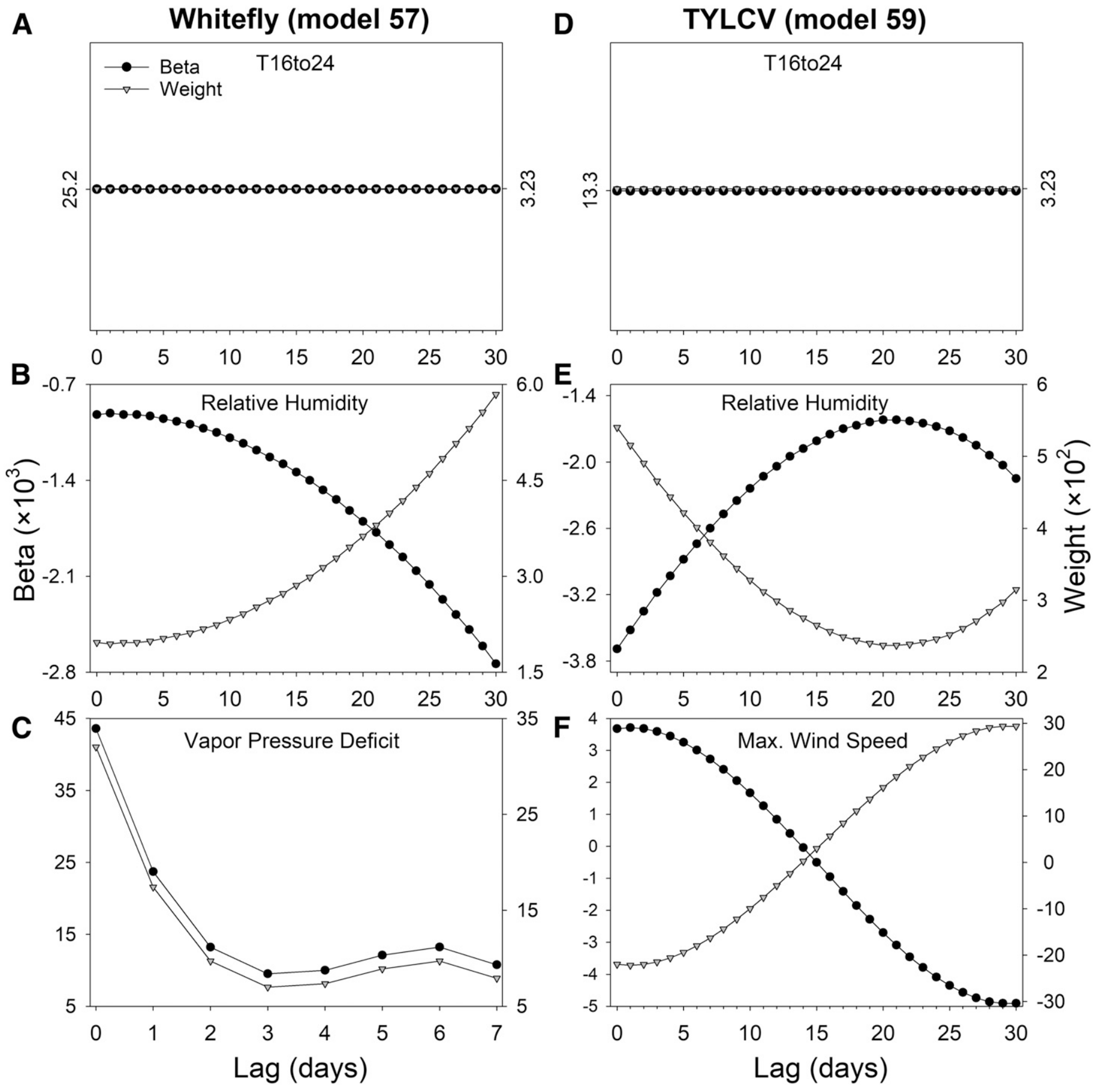

Fig. 7. Estimated $\beta$ parameters (black circles) and weights (gray triangles) at lagged days for $\log ($ whitefly +0.01 ) according to model 57 variables $\mathbf{A}, 16 \leq$ average temperature $\left(\mathrm{T}_{\mathrm{avg}}\right) \leq 24^{\circ} \mathrm{C}$ (T16to24); $\mathbf{B}$, relative humidity $(\mathrm{RH})$; and $\mathbf{C}$, vapor pressure deficit (VPD) and for $\log$ (tomato yellow leaf curl virus [TYLCV] +0.01 ) according to model 59 variables $\mathbf{D}, 16 \leq \mathrm{T}_{\mathrm{avg}} \leq 24^{\circ} \mathrm{C}$ (T16to24); E, relative humidity $(\mathrm{RH})$; and $\mathbf{F}$, maximum wind speed $\left(\mathrm{W}_{\max }\right)$. 
impress upon growers the need for collective action. True AWPM will require significant grower buy-in on an agreed-upon set of rules and practice (Sherman et al. 2019).
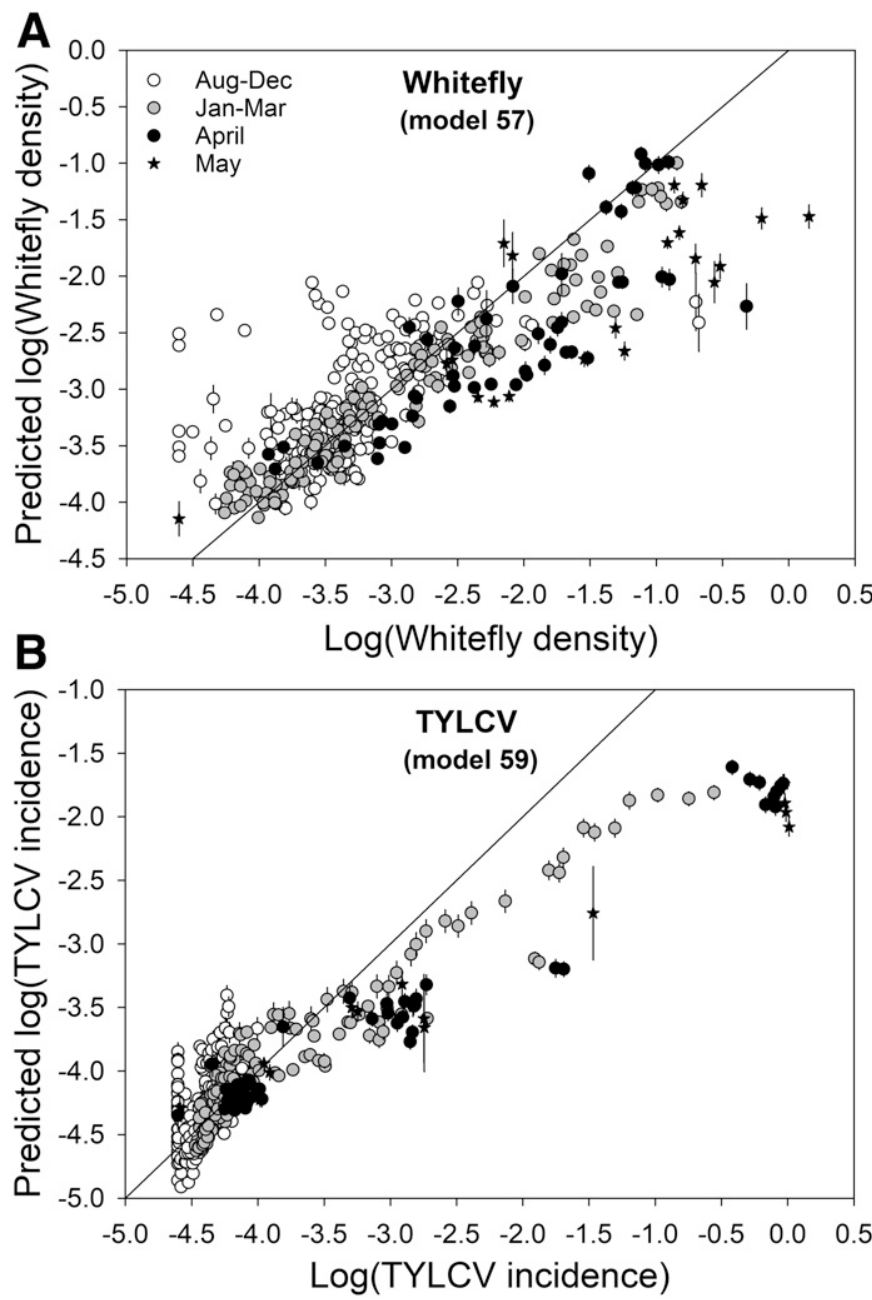

Fig. 8. Plots of $\mathbf{A}, \log ($ whitefly +0.01$)$ observed and predicted by model 57 and $\mathbf{B}, \log$ (tomato yellow leaf curl virus $[\mathrm{TYLCV}]+0.01)$ observed and predicted by model 59 for the entire 6-year data set. Each symbol represents the daily average for a given year (years are not distinguishable), with $n$ per symbol ranging from a minimum of 3 to a maximum of 525 (interquartile range 103 to 317). The standard error of the mean is the vertical line through each symbol. Symbols are further categorized by the month in which the data were collected, with emphasis placed on the last 2 months of the production year.

TABLE 9. Top five linear mixed models with fit statistics for predicting the logarithm of the daily tomato yellow leaf curl virus (TYLCV) incidence

\begin{tabular}{lcccc}
\hline Model $^{\mathrm{x}}$ & AICC $^{\mathrm{y}}$ & $\mathrm{CCC}^{\mathrm{z}}$ & Model weight & Weight ratio \\
\hline 59: T16to24, RH, W & 174488.3 & 0.7174 & 0.995 & $\ldots$ \\
23: Tgt25, RH, VPD & 174498.9 & 0.7171 & 0.005 & 200.3 \\
52: T16to24, P, RH & 174635.6 & 0.7163 & $1.03 \times 10^{-32}$ & $9.68 \times 10^{31}$ \\
57: T16to24, RH, VPD & 175306.7 & 0.7134 & $1.93 \times 10^{-178}$ & $5.17 \times 10^{177}$ \\
58: T16to24, RH, W & 175518.7 & 0.7179 & $1.78 \times 10^{-224}$ & $5.60 \times 10^{223}$ \\
\hline
\end{tabular}

${ }^{\mathrm{x}}$ Model variables correspond to average temperature between 16 and $24^{\circ} \mathrm{C}$ (T16to24), temperature greater than $25^{\circ} \mathrm{C}$ (Tgt25), daily average temperature $\left(\mathrm{T}_{\text {avg }}\right)$, maximum temperature $\left(\mathrm{T}_{\max }\right)$, minimum temperature $\left(\mathrm{T}_{\min }\right)$, relative humidity (RH), vapor pressure deficit (VPD), total precipitation (P), maximum wind speed $\left(\mathrm{W}_{\max }\right)$, and average wind speed $\left(\mathrm{W}_{\text {avg }}\right)$. Variables were distributed over 31 days (except for VPD, which was distributed over 8 days). Polynomial order was $d=0$ for T16to24 and Tgt25, $d=1$ for $\mathrm{P}$, and $d=3$ for $\mathrm{RH}, \mathrm{VPD}, \mathrm{P}, \mathrm{W}_{\max }$, and $\mathrm{W}_{\mathrm{avg}}$.

y Corrected Akaike Information Criterion.

${ }^{\mathrm{z}}$ Concordance correlation coefficient.
"The overall premise [of AWPM] is that a number of serious economic pests can be effectively managed using an organized and coordinated attack on their populations over a large area rather than by using a field-by-field approach" (Faust 2008). Between 1992 and 2002, the United States Department of Agriculture-Agricultural Research Service funded a large initiative to develop AWPM for B. tabaci in Arizona, California, and Florida (Henneberry et al. 2002). The 10-year project successfully led to a much deeper understanding of several aspects of whitefly biology, epidemiology, and IPM tactics for management; however, true AWPM was not achieved. In reviewing the 10-year progress report, it was clear that the fundamental knowledge needed to implement AWPM was lacking at the time. Results presented here provide some of the necessary information and basic framework to begin the design and possible implementation of AWPM for this pathosystem.

Finally, it should be noted that other factors not considered in these models also effect whitefly and TYLCV populations; namely, cultivar, pesticide usage, whitefly biotype, or virus species, to name a few. These variables have a known impact on epidemic development and their absence may be one of the reasons why model 59 underpredicted TYLCV incidence at higher incidence values (Fig. 8B). For example, in most commercial production, pest management practices are greatly curtailed toward the end of the season because of the belief that any increase in whiteflies or TYLCV just before and during the harvest period will have minimal impact on yield. Thus, TYLCV and whitefly numbers often spike at this time of year. Yet, despite the end of the season weather sharing similar attributes with the beginning of the season (hot and humid), the values of the response variables (i.e., TYLCV incidence and whitefly density) are nearly the opposite: low at the beginning of the season when whitefly is managed intensively, and high at the end when management is relaxed. Finally, although it is a significant undertaking to collect and process 6 years of data collected over a large region, the results still represent only a mere snapshot of the agroecosystem. The environmental conditions, surrounding landscape, horticultural and pest management practices, and market conditions change continuously. Thus, augmenting the current data set with more recent data to account for said changes should be sought if the goal is to obtain increasingly accurate predictions.

It is beyond the scope of the current study to independently validate the proposed AWPM approach; however, future investigations could help determine whether whitefly can be effectively managed on a predictive, areawide basis compared with current calendar or scouting-based management.

\section{APPENDIX 1}

Weather data interpolation. Weather data for each field per year was spatially interpolated via universal kriging according to an isotropic exponential variogram in PROC MIXED (version 9.4; SAS) (Littell et al. 2006), factoring into account correlations of weather variables with elevation (i.e., a highly significant factor despite Florida's relative lack of topography); distances from field centroids to the Atlantic Ocean, Gulf of Mexico, Lake Okeechobee, and the nearest water body; and interactions thereof. Anisotropic relationships were examined but did not produce superior fits in the current study. Distances were calculated in ArcMap using the World Water Bodies layer package (DeLorme Publishing Company, Inc., Yarmouth, ME). Elevations of fields were set equal to that of the nearest National Geodetic Survey point (April 2013 data) (https://www.ngs.noaa.gov/datasheets/). Calculations within ArcMap were performed using an Albers projection in combination with the North American 1983 HARN Geographic Coordinate System and Datum.

Precision of the estimated (= interpolated) weather variables was quantified using the equation [(standard error)/(estimate +1$)]$. This measurement was $<0.9$-indicating high precision-for all interpolated weather variables, with the exception of $\mathrm{T}_{\min }$ and $\mathrm{T}_{\max }$ 
in year $1, \mathrm{~W}_{\text {max }}$ in years 3 and 4 , and $\mathrm{P}$ over all examined years ( $\mathrm{P}$ is notorious for being highly spatially variable) (Supplementary Fig. $\mathrm{S} 1)$. With respect to year 1 results, fewer weather stations were operational during the first year. During subsequent years, the precision of estimated temperatures was better, with interquartile ranges being less than 0.1 (Supplementary Fig. S1A and B). Wind speed variability was fairly consistent over the 6 years, with median values being less than 0.15 and 0.2 for $\mathrm{W}_{\text {avg }}$ and $\mathrm{W}_{\text {max }}$, respectively (Supplementary Fig. S1C and D). The precision of estimated RH was the highest, because interquartile ranges thereof were consistently below 0.05 (Supplementary Fig. S1E). P was the variable with the greatest estimated standard errors relative to estimates (Fig. 7; Supplementary Fig. S1F). Median variability proportions ranged from about 4 to 5 , with interquartile ranges spanning approximately 2 to 7 .

\section{APPENDIX 2}

Influence analysis. To assess model performance under available data, influence statistics were calculated using the MIXED procedure in SAS. To counteract computational memory limitations of the MIXED procedure when calculating influence statistics under the specific dataset examined with the incorporated covariance parameters and error structure, we executed model dimensionality reduction. This involved leveraging the random effects solution obtained under the full model specification (equation A2.1) for $T(L)_{i j}$ and $G_{\mathrm{r}}$, adjusting $Y_{i j r t}$ into $Y^{*}$ as a function of the resulting random effects solutions, holding the remaining covariance parameters at the estimates obtained under the full model specification, and fitting the reduced dimensionality model to $Y_{i j r t} *$. Algebraic rearrangement yielded the following equation:

$$
Y_{i j r t} *=\alpha+\sum_{\mathrm{k}=0}^{\mathrm{d}} \eta_{\mathrm{k}}^{(f)} Z_{(k) i j t}^{(f)}+e_{i j r t}
$$

where $Y_{i j r t} *=Y_{i j r t}-\left[G_{r}+T(L)_{i j}\right]$. Parameter estimates obtained under the reduced model were stable compared with the full model. Influence statistics obtained in the subsequent analysis included log-likelihood distance $(l)$ and Cook's distance $\left(C_{D}\right)$. The $l$ statistic measures the overall change in the model log-likelihood of the complete dataset when evaluated with estimates that represent removal of an individual location-year, whereas $C_{D}$ is an indication of the change in the overall fixed-effects parameter vector. Fitted models for both whitefly density and TYLCV incidence were notably robust to field-years included in the analyses in light of results not markedly changing following removal of individual field-years. The critical value for $l$ was 74 , based on the $75^{\text {th }}$ percentile of the $\chi^{2}$ distribution, and the critical value for $C_{D}$ was 0.455 , based on the $50^{\text {th }}$ percentile of the $F$ distribution (Cook and Weisberg 1982; Littell et al. 2006; Paul et al. 2007). With regards to the whitefly density analysis (model 57), field-year 164 in year 1 was the only field-year with a $C_{D}$ above the critical value (Supplementary Fig. S2A and C). The corresponding $l$ for this field-year, however, was considerably lower than the respective critical value. Following the removal of field-year 164 from the whitefly density analysis, marginal parameter $\left(\beta^{*}=\Sigma \beta_{Z(f)}\right)$ estimates for T16to24, RH, and VPD would have been 771.9, -25.9 , and 145.2, respectively, which would have been somewhat smaller for T16to24 and somewhat larger for RH and VPD. The corresponding $\mathrm{CCC}$ for the model under the reduced data would have been 0.7022 . Because removal of field-year 164 did not notably improve the overall performance or reliability of the model, inclusion of this field-year was maintained to allow the analysis to
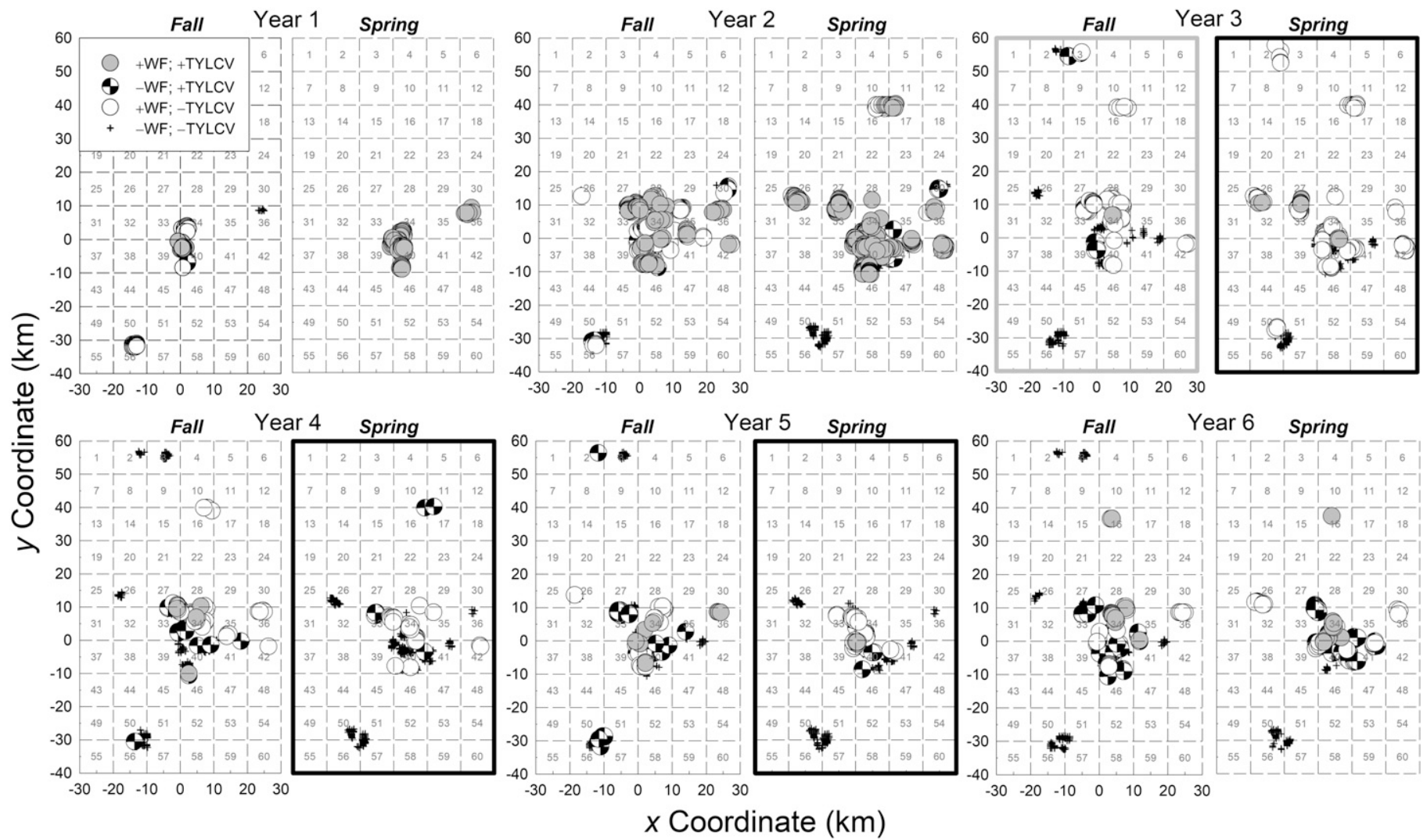

Fig. 9. Mapped tomato yellow leaf curl virus (TYLCV) incidences and whitefly (WF) densities in all fields in production in the southwestern Florida study area at the specified time during the six production years studied. Circular symbols represent whether TYLCV, WF, or both exceeded the threshold of 5\% and 0.1 WF/ plant, respectively, during the season and are sized to a 3-km radius. Plus symbols (+) are fields where neither threshold was exceeded over the course of the season. Symbols are centered on the centroid locations of the respective field. Maps with a thickened border highlight seasons that experienced a tropical weather event (gray) or a significant freeze event (black). 
utilize all available data. Under the TYLCV incidence analysis (model 59), all field-years were below the respective critical values for $l$ and $C_{D}$ (Supplementary Fig. S2B and D).

Model performance assessment following partitioning into training and testing datasets. To further assess model performance, whitefly density and TYLCV incidence datasets were each split into training and testing datasets comprising 70 and $30 \%$ of the total data, respectively, and modeled according to linear mixed model 57 (whitefly density) or linear mixed model 59 (TYLCV incidence). The training dataset for whitefly incidence yielded a CCC of 0.6828 and the corresponding testing dataset exhibited a similar but slightly lower CCC of 0.6591 based on the parameter estimates obtained following analysis of the training dataset. Analysis of the training dataset for TYLCV incidence yielded a CCC of 0.7178 , whereas the corresponding testing dataset was associated with an analogous CCC of 0.69717 under the parameter estimates resulting from fitting the model to the training dataset. Parameter estimates for the two models fitted to the training data are shown in Supplementary Tables S1 and S2. The close similarities of the CCC reliability statistics of the test datasets compared with the training datasets combined with the results obtained under the above influence analyses corroborate the stability of model performance among the partitioned datasets and demonstrate a lack of overly influential fieldyears used in the modeling.

\section{ACKNOWLEDGMENTS}

We thank K. Poole, G. Hess, and C. Vanderspool for their excellent technical assistance; and G. McAvoy, M. Verbeck, and K. Short for valuable discussions, help with field mapping, and data collection.

\section{LITERATURE CITED}

Akad, F., Jacobi, J. C., and Polston, J. E. 2007. Identification of Tomato yellow leaf curl virus and Tomato mottle virus in two counties in Alabama. Plant Dis. 91:906.

Batten, D. S., and Thornton, D. L. 1983. Polynomial distributed lags and the estimation of the St. Louis equation. Federal Reserve Bank St. Louis Rev. 65:13-25.

Buck, A. L. 1981. New equations for computing vapor pressure and enhancement factor. J. Appl. Meteorol. 20:1527-1532.

Butler, G. D., Jr., Henneberry, T. J., and Clayton, T. E. 1983. Bemisia tabaci (Homoptera: Aleyrodidae): Development, ovisposition, and longevity in relation to temperature. Ann. Entomol. Soc. Am. 76:310-313.

Campbell, P. R., Cremer, J. E., Roach, R. L., Steele, V., Subramaniam, S., Sivasubramaniam, V., Monsour, C., Mullins, T., Persley, D. M., and Gambley, C. F. 2017. Towards area wide management of insect vectored viruses of tomatoes in the Bowen district. Virus Res. 241:228-235.

Carisse, O., Morissette-Thomas, V., and Van der Heyden, H. 2013. Lagged association between powdery mildew leaf severity, airborne inoculum, weather, and crop losses in strawberry. Phytopathology 103:811-821.

Chen, G., Pan, H., Xie, W., Wang, S., Wu, Q., Fang, Y., Shi, X., and Zhang, Y. 2013. Virus infection of a weed increases vector attraction to and vector fitness on the weed. Sci. Rep. 3:2253.

Chen, Y. 2013. New approaches for calculating Moran's index of spatial association. PLoS One 8:e68336.

Cook, R. D., and Weisberg, S. 1982. Residuals and Influence in Regression. Chapman and Hall/CRC, New York, NY, U.S.A.

Fang, Y., Jiao, X., Wen, X., Wang, S., Wu, Q., Shi, X., Chen, G., Su, Q., Yang, X., Pan, H., and Zhang, Y. 2013. Tomato yellow leaf curl virus alters the host preferences of its vector Bemisia tabaci. Sci. Rep. 3:2876.

Faust, R. M. 2008. General introduction to areawide pest management. Pages 1-14 in: Areawide Pest Management: Theory and Implementation. O. Koul, G. W. Cuperus, and N. Elliott, eds. CAB International, Wallingford, U.K.

Fourie, P., Schutte, T., Serfontein, S., and Swart, F. 2013. Modeling the effect of temperature and wetness on Guignardia pseudothecium maturation and ascospore release in citrus orchards. Phytopathology 103:281-292.

Gerling, D., Horowitz, A. R., and Baumgaertner, J. 1986. Autecology of Bemisia tabaci. Agric. Ecosyst. Environ. 17:5-19.

Henneberry, T. J., Faust, R. M., Jones, W. A., and Perring, T. M. eds. 2002. Silverleaf Whitefly: National Research, Action, and Technology Transfer Plan (formerly Sweetpotato Whitefly, Strain B). In: Fourth Annu. Rev. Second 5-Year Plan Final Rep. 1992-2002, San Diego, CA. United States Department of Agriculture-Agricultural Research Service.
Hu, X., Madden, L. V., Edwards, S., and Xu, X. 2015. Combining models is more likely to give better predictions than single models. Phytopathology 105:1174-1182.

Ingram, D. M., and Henn, A. 2001. First report of Tomato yellow leaf curl virus in Mississippi. Plant Dis. 85:1287.

Legarrea, S., Barman, A., Marchant, W., Diffie, S., and Rajagopalbabu, S. 2015. Temporal effects of a Begomovirus infection and host plant resistance on the preference and development of an insect vector, Bemisia tabaci, and implications for epidemics. PLoS One 10:e0142114.

Lin, K., Wu, K., Zhang, Y., and Guo, Y. 2007. Overwintering and population dynamics of Bemisia tabaci biotype $\mathrm{B}$ in greenhouse during the spring in northern China. Crop Prot. 26:1831-1838.

Lin, L. I.-K. 1989. A concordance correlation coefficient to evaluate reproducibility. Biometrics 45:255-268.

Ling, K. S., Simmons, A. M., Hassell, R. L., Keinath, A. P., and Polston, J. E. 2006. First report of Tomato yellow leaf curl virus in South Carolina. Plant Dis. 90:379.

Littell, R. C., Milliken, G. A., Stroup, W. W., Wolfinger, R. D., and Schabenberger, O. 2006. SAS System for Mixed Models, 2nd ed. SAS Institute Inc., Cary, NC, U.S.A.

Madden, L. V., Hughes, G., and van den Bosch, F. 2007. The Study of Plant Disease Epidemics. American Phytopathological Society, St. Paul, MN, U.S.A.

Madden, L. V., and Paul, P. A. 2010. An assessment of mixed-modeling approaches for characterizing profiles of time-varying response and predictor variables. Phytopathology 100:1015-1029.

Maluta, N. K. P., Garzo, E., Moreno, A., Lopes, J. R. S., and Fereres, A. 2014. Tomato yellow leaf curl virus benefits population growth of the Q biotype of Bemisia tabaci (Gennadius) (Hemiptera: Aleyrodidae). Neotrop. Entomol. 43:385-392.

Momol, M. T., Simone, G. W., Dankers, W., Sprenkel, R. K., Olson, S. M., Momol, E. A., Polston, J. E., and Hiebert, E. 1999. First report of Tomato yellow leaf curl virus in south Georgia. Plant Dis. 83:487.

Morilla, G., Janssen, D., García-Andrés, S., Moriones, E., Cuadrado, I. M., and Bejarano, E. R. 2005. Pepper (Capsicum annuum) is a dead-end host for Tomato yellow leaf curl virus. Phytopathology 95:1089-1097.

Muñiz, M., and Nombela, G. 2001. Differential variation in development of the B- and Q-biotypes of Bemisia tabaci (Homoptera: Aleyrodidae) on sweet pepper at constant temperatures. Environ. Entomol. 30:720-727.

Navas-Castillo, J., Sánchez-Campo, S., Díaz, J. A., Sáez-Alonso, E., and Moriones, E. 1999. Tomato yellow leaf curl virus-IS causes a novel disease of common bean and severe epidemics in tomato in Spain. Plant Dis. 83:29-32.

Pan, H., Chu, D., Liu, B., Shi, X., Guo, L., Xie, W., Carrière, Y., Li, X., and Zhang, Y. 2013. Differential effects of an exotic plant virus on its two closely related vectors. Sci. Rep. 3:2230.

Paul, P. A., Lipps, P. E., De Wolf, E., Shaner, G., Buechley, G., Adhikari, T., Ali, S., Stein, J., Osborne, L., and Madden, L. V. 2007. A distributed lag analysis of the relationship between Gibberella zeae inoculum density on wheat spikes and weather variables. Phytopathology 97:1608-1624.

Picó, B., Díez, M. J., and Nuez, F. 1996. Viral diseases causing the greatest economic losses to the tomato crop. II. The tomato yellow leaf curl virus-A review. Sci. Hortic. (Amsterdam) 67:151-196.

Polston, J. E., Cohen, L., Sherwood, T. A., Ben-Joseph, R., and Lapidot, M. 2006. Capsicum species: Symptomless hosts and reservoirs of Tomato yellow leaf curl virus. Phytopathology 96:447-452.

Polston, J. E., McGovern, R. J., and Brown, L. G. 1999. Introduction of tomato yellow leaf curl virus in Florida and implications for the spread of this and other geminiviruses of tomato. Plant Dis. 83:984-988.

Polston, J. E., Schuster, D. J., and Taylor, J. E. 2009. Identification of weed reservoirs of Tomato yellow leaf curl virus in Florida. Pages 32-33 in: Florida Tomato Institute Proceedings. E. Simone, C. Snodgrass, and M. Ozores-Hampton, eds. University of Florida Institute of Food and Agricultural Sciences, Gainesville, FL, U.S.A.

Pusag, J. C. A., Jahan, S. M. H., Lee, K.-S., Lee, S., and Lee, K.-Y. 2012. Upregulation of temperature susceptibility in Bemisia tabaci upon acquisition of Tomato yellow leaf curl virus (TYLCV). J. Insect Physiol. 58:1343-1348.

Riley, D. G., and Srinivasan, R. 2019. Integrated management of Tomato yellow leaf curl virus and its whitefly vector in tomato. J. Econ. Entomol. 112:1526-1540.

Rossi, V., Salinari, F., Pattori, E., Giosuè, S., and Bugiani, R. 2009. Predicting the dynamics of ascospore maturation of Venturia pirina based on environmental factors. Phytopathology 99:453-461.

Sawada, M. 1999. Rookcase: An Excel 97/2000 Visual Basic (VB) add-in for exploring global and local spatial autocorrelation. Bull. Ecol. Soc. Am. 80: 231-234.

Schabenberger, O., and Pierce, F. J. 2002. Contemporary Statistical Models for the Plant and Soil Sciences. CRC Press, Boca Raton, FL, U.S.A.

Sherman, J., Burke, J. M., and Gent, D. H. 2019. Cooperation and coordination in plant disease management. Phytopathology 109:1720-1731. 
Schuster, D. J., Mann, R., and Gilreath, P. R. 2006. Whitefly resistance update and proposed mandated burn down rule. Pages 24-28 in: Florida Tomato Institute Proceedings. P. Gilreath and K. Cushman, eds. University of Florida Institute of Food and Agricultural Sciences, Gainesville, FL, U.S.A.

Schuster, D. J., Stansly, P. A., Gilreath, P. R., and Polston, J. E. 2008. Management of Bemisia tabaci, TYLCV, and insecticide resistance in Florida vegetables. J. Insect Sci. 8:43-44

Schwartz, J. 2000. The distributed lag between air pollution and daily deaths. Epidemiology 11:320-326.

Simmons, A. M., and Elsey, K. D. 1995. Overwintering and cold tolerance of Bemisia argentifolii (Homoptera: Aleyordidae) in Coastal South Carolina. J. Entomol. Sci. 30:497-506.

Smith, H. A., Nagle, C. A., MacVean, C. A., and McKenzie, C. L. 2016. Susceptibility of Bemisia tabaci MEAM1 (Hemiptera: Aleyrodidae) to imidacloprid, thiamethoxam, dinotefuran, and flupyradifurone in south Florida. Insects 7:57.

Smith, H. A., Nagle, C. A., MacVean, C. A., Vallad, G. E., van Santen, E., and Hutton, S. F. 2019. Comparing host plant resistance, repellent mulches, and at-plant insecticides for management of Bemisia tabaci MEAM1 (Hemiptera: Aleyrodidae) and Tomato yellow leaf curl virus. J. Econ. Entomol. 112:236-243.

Smith, H. A., Seijo, T. E., Vallad, G. E., Peres, N. A., and Druffel, K. L. 2015. Evaluating weeds as hosts of Tomato yellow leaf curl virus. Environ. Entomol. 44:1101-1107.
Stansly, P. A., Smith, H. A., Seal, D. R., McAvoy, E., Polston, J. E., Gilreath, P. R., and Schuster, D. J. 2015. Management of Whiteflies, WhiteflyTransmitted Plant Virus, and Insecticide Resistance for vegetable Production in Southern Florida. ENY-735. Entomology and Nematology Department, Florida Cooperative Extension Service, Institute of Food and Agricultural Sciences, University of Florida, Gainesville, FL, U.S.A.

Teklehaimanot, H. D., Lipsitch, M., Teklehaimanot, A., and Schwartz, J. 2004. Weather-based prediction of Plasmodium falciparum malaria in epidemicprone regions of Ethiopia I. Patterns of lagged weather effects reflect biological mechanisms. Malar. J. 41:1-11.

Turechek, W. W., Roberts, P. D., Stansly, P. A., Webster, C. G., Kousik, C. S., and Adkins, S. 2014. Spatial and temporal analysis of Squash vein yellowing virus infection in watermelon. Plant Dis. 98:1671-1680.

USDA-NASS. 2012. Agricultural Statistics Annual. Vegetables and melons. United States Department of Agriculture-National Agricultural Statistics Service. https://www.nass.usda.gov/Publications/Ag_Statistics/2012/chapter04. pdf

USDA-NASS. 2018. Agricultural Statistics Annual. Vegetables and melons. United States Department of Agriculture-National Agricultural Statistics Service. https://www.nass.usda.gov/Publications/Ag_Statistics/2018/Chapter04. pdf

Xiao, N., Pan, L.-L., Zhang, C.-R., Shan, H.-W., and Liu, S.-S. 2016. Differential tolerance capacity to unfavorable low and high temperatures between two invasive whiteflies. Sci. Rep. 6:24306. 